\title{
Bioactive lipids-based therapeutic approach to COVID-19 and other similar infections
}

\section{Type}

Review paper (After Acceptance of EiC)

\section{Keywords}

macrophages, inflammation, polyunsaturated fatty acids, prostaglandins, resolvins, maresins, lipoxin A4, COVID-19, protectins, Bioactive lipids

\begin{abstract}
It is suggested that COVID-19 (coronavirus) and other enveloped viruses can be inactivated by bioactive lipids.

Bioactive lipids (BALs) AA, gamma-linolenic acid (GLA), dihomo-GLA (DGLA), eicosapentaenoic acid (EPA), docosahexaenoic acid (DHA) are precursors to anti-inflammatory metabolites prostaglandin E1, lipoxin A4, resolvins, protectins and maresins that enhance phagocytosis of macrophages and leukocytes to clear debris, enhance microbial clearance and wound healing to restore homeostasis. BALs influence cell membrane fluidity and thus, prevent SARS-CoV-2, influenza, and Arboviruses (such as Chikungunya, Dengue, Zika) to infect the target cells. BALs modulate the generation of M1 and M2 macrophages. Mesenchymal and adipose tissue-derived stem cells secrete LXA4 and other BALs to bring about their beneficial actions in COVID-19. Prostaglandin E2 (PGE2), derived from arachidonic acid, triggers generation of anti-inflammatory lipoxin A4 and thus, modulates pathogenesis of COVID-19. AA, the precursor to both PGE2 and LXA4, and thus, is suited to prevent and ameliorate COVID-19.
\end{abstract}


$\underline{\text { Review for } A M S}$

\begin{abstract}
Bioactive lipids-based therapeutic approach to COVID-19 and other similar infections Undurti N Das, MD, DSc, FAMS, FRSC

UND Life Sciences, 2221 NW $5^{\text {th }}$ St, Battle Ground, WA 98604, USA;
\end{abstract}

BioScience Research Centre and Department of Medicine, GVP Medical College and Hospital, Visakhapatnam-530048, India and

International Research Centre, Biotechnologies of the third Millennium, ITMO University, Saint-Petersburg, Russia.

E-Mail: undurti@hotmail.com; Ph; 508-904-5376

\begin{abstract}
Background: COVID-19 is a pandemic caused by SARS-CoV-2 infection. Development of specific anti-viral compounds and effective vaccine(s) is likely to take considerable time and efforts. But more fundamental issue is how under physiological conditions, several microbial infections are effectively controlled by the immune and non-immune system(s) of the body. Evidence suggests that epithelial and other cells and T, NK, and other immunocytes release bioactive lipids especially arachidonic acid (AA) in response to microbial infections to inactivate them and upregulate the immune system.

Hypothesis: It is suggested that COVID-19 (coronavirus) and other enveloped viruses including severe acute respiratory syndrome (SARS-CoV-1 of 2002-2003) and Middle East respiratory syndrome (MERS; 2012-ongoing) and hepatitis B and C (HBV and HCV) can be inactivated by bioactive lipids.
\end{abstract}

Discussion: The released bioactive lipids such as AA, gamma-linolenic acid (GLA, dihomo-GLA (DGLA), eicosapentaenoic acid (EPA), docosahexaenoic acid (DHA) are precursors to antiinflammatory metabolites prostaglandin E1, lipoxin A4, resolvins, protectins and maresins that enhance phagocytosis of macrophages and leukocytes to clear debris from the site(s) of infection and injury, enhance microbial clearance and wound healing to restore homeostasis. The positive and negative feedback regulation among pro- and anti-inflammatory cytokines and bioactive lipids is essential in the recovery from COVID-19 and other similar illnesses. Bioactive lipids influence cell membrane fluidity and thus, prevent SARS-CoV-2, influenza, and Arboviruses 
(such as Chikungunya, Dengue, Zika) to infect the target cells. Bioactive lipids modulate the generation of $\mathrm{M}_{1}$ and $\mathrm{M} 2$ macrophages and activity of other immunocytes. Mesenchymal and adipose tissue-derived stem cells secrete LXA4 and other bioactive lipids to bring about their beneficial actions in COVID-19. Prostaglandin E2 (PGE2), derived from arachidonic acid, an important bioactive lipid, modulates inflammatory events, triggers generation of antiinflammatory lipoxin A4 and other similar compounds and thus, modulates pathogenesis of COVID-19. AA, the precursor to both PGE2 and LXA4, and thus, is more suited to prevent and ameliorate COVID-19. Bioactive lipids regulate vasomotor tone, inflammation, thrombosis, immune response, inactivate enveloped viruses, regulate $\mathrm{T}$ cell proliferation and secretion of cytokines, stem cell survival, proliferation and differentiation, and leukocyte and macrophage functions, JAK kinase activity and neutrophil extracellular traps, events that attest to their critical role in COVID-19.

Conclusions: Hence, it is proposed that studies need to be performed to explore the anti-viral actions of various bioactive lipids against SARS-CoV-2, SARS, MERS, HCV, and HBV. Based on the current evidence, it is suggested that oral and/or parenteral administration of bioactive lipids especially AA could be exploited as a potential therapeutic approach in the prevention and management of COVID-19 and other similar infections.

Keywords: Bioactive lipids, essential fatty acids, prostaglandins, polyunsaturated fatty acids, lipoxin A4, resolvins, protectins, maresins, inflammation, macrophages, COVID-19, SARS-CoV2.
Abbreviations:
BALs $=$ Bioactive lipids
LXA4 = lipoxin A4
PGs $=$ Prostaglandins
LTs $=$ Leukotrienes
TXs $=$ Thromboxanes
$\mathrm{RBD}=$ Receptor binding domain

SARS $=$ Severe acute respiratory syndrome 
COVID-19 = Coronavirus disease 2019

$\mathrm{ACE}=$ Angiotensin converting enzyme

ACE2 = Angiotensin converting enzyme 2

$\mathrm{ARDS}=$ Acute respiratory distress syndrome

TMPRSS $2=$ Transmembrane protease serine 2

$\mathrm{IL}=$ Interleukin

$\mathrm{TNF}=$ Tumor necrosis factor

ROS $=$ Reactive oxygen species

$\mathrm{NO}=$ Nitric oxide

MERS $=$ Middle East respiratory syndrome

$\mathrm{HBV}=$ Hepatitis $\mathrm{B}$ virus

$\mathrm{HCV}=$ Hepatitis $\mathrm{C}$ virus

$\mathrm{CNS}=$ Central nervous system

AngII = Angiotensin II

LGE = Late-gadolinium enhancement

$\mathrm{RV}=$ Right ventricle

$\mathrm{LV}=$ Left ventricle

$\mathrm{ECMO}=$ Extracorporeal membrane oxygenation

MRI = Magnetic resonance imaging

$\mathrm{CRP}=\mathrm{C}$-reactive protein

PLA2 $=$ Phospholipase A2

PLC $=$ Phospholipase $\mathrm{C}$

PLD $=$ Phospholipase $\mathrm{D}$

COX $=$ Cyclo-oxygenase 
LOX $=$ Lipoxygenase

PGDH $=$ Prostaglandin dehydrogenase

$\mathrm{AA}=$ Arachidonic acid

GLA $=$ Gamma-linolenic acid

DGLA = Dihomo-gamma-linolenic acid

$\mathrm{EPA}=$ Eicosapentaenoic acid

DHA =Docosahexaenoic acid

LA =Linoleic acid

ALA =Alpha-linolenic acid

$\mathrm{CO}=$ Carbon monoxide

$\mathrm{H} 2 \mathrm{~S}=$ Hydrogen sulfide

MSCs =Mesenchymal stem cells

MIF = Macrophage inhibitory factor

HMGB1 = High mobility group box 1

NK = Natural killer

PMNs = polymorphonuclear cells

IFN $=$ Interferon

HETE $=$ Hydroxyeicosatetraenoic acid

HPETE $=$ Hydroperoxyeicosatetraenoic acid 


\section{Introduction}

Severe acute respiratory syndrome-coronavirus 2 (SARS-CoV-2), the etiologic agent of the current outbreak of coronavirus disease 2019 (COVID-19), presents great similarity to the other coronaviruses SARS-CoV-1 and MERS-CoV, which caused the severe acute respiratory syndrome (SARS in 2002-2003) and Middle East respiratory syndrome (MERS from 2012ongoing) outbreaks, respectively. These are enveloped viruses and share a great homology in their structures [1].

SARS-CoV-2 virus particles contain proteins known as spikes protruding from their surface. These spike proteins bind to human cells to enable the viral membrane to fuse with the cell membrane that facilitate the viral genes to enter the host cell to produce its actions (see Figure 1 for structure of SARS-CoV-2). Even though the sequences and structures of the spikes of SARS-CoV-2 and SARS-CoV-1 are similar, antibodies directed against SARS-CoV-1 do not bind to the SARS-CoV-2 spike protein $[2,3]$ though some amount of limited cross reactivity has bene reported [4-6]. . This indicates that more specific antibodies need to be generated for their potential use in humans.

Current strategies that are being employed against COVID-19 include inhibitors of viral entry into cells, viral replication, and RNA synthesis. SARS-CoV-2 utilizes angiotensinconverting enzyme $2(\mathrm{ACE} 2)$ and the cellular protease transmembrane protease serine 2 (TMPRSS2) to enter target cells. Hence, chemicals that act on these two ligands are under development. But these strategies take considerable time to come to the clinic. SARS-CoV-2 spike glycoprotein (S protein) is cleaved into $\mathrm{S} 1$ and $\mathrm{S} 2$ subunits at the time of infection. S1 contains the receptor binding domain $(\mathrm{RBD})$ that binds to the peptidase domain (PD) of ACE2, while $\mathrm{S} 2$ is needed for membrane fusion. When $\mathrm{S} 1$ binds to the $\mathrm{ACE} 2$, another cleavage site on $\mathrm{S} 2$ is exposed that is cleaved by host proteases to facilitate viral infection. It is noteworthy that the $\mathrm{S}$ protein of SARS-CoV-2 exploits ACE2 for host infection [7]. ACE2 is expressed in many tissues including but not limited to lungs, heart, kidney, and intestines which are the targets of the SARS-CoV-2. ACE2 is needed for the maturation of angiotensin to control vasoconstriction and blood pressure. A reduced expression of ACE2 is associated with cardiovascular diseases that explains why many with COVID-19 may develop myocardia damage and heart failure (see Figure 1 for the structure of SARS-CoV-2; and similarities and differences between Swine flu 
A/Mexico/o9 (H1N1) virus and SARS-CoV-2; Table 1 for similarities and differences between influenza and corona viruses and Figure 2 for the role of ACE2 in humans).

\section{Historical aspects of influenza}

Influenza, or flu, attacks principally the respiratory system and is highly contagious. The infection can spread from one person to the other through droplets generated during cough, sneeze or talk. These droplets can travel into the air and eventually be inhaled by others leading to spread of the disease. In addition, the virus can spread by touch when one person touches any infected surface with the virus and then touches his or her mouth, eyes, or nose. In the USA, during the flu season more than 200,000 are hospitalized for flu-related complications. Young children, elderly (>65yrs), pregnant women and people with asthma, diabetes mellitus and/or heart disease are particularly vulnerable to risk of flu-related complications, including but not limited to pneumonia, myocarditis, central nervous system (CNS), eye, ear and sinus infections and bronchitis. Recent studies suggested that SARS-CoV-2 can infect neuronal cells that can result in encephalitis-like clinical presentation, produce thrombosis of the cerebral veins and arteries leading to stroke and other complications. It needs to be noted that post-COVID-19 manifestations include persistent headache, memory loss, confusion, inability to concentrate, breathlessness, cough, low grade fever, muscle pains and unexplained weakness [8-13].

It is noteworthy that there have been several influenza pandemics. The first flu pandemic recorded in 1918 termed as "Spanish flu" (this is a misnomer as it did not originate in Spain and is more aptly termed as "1918 influenza pandemic," or the "1918 flu pandemic,") in which the death toll is estimated $\sim 20$ million to 50 million worldwide. The flu pandemic of 1957-1958 killed $\sim 2$ million people worldwide. The pandemic of 19681969 killed $\sim 1$ million, whereas > 12,000 Americans died during the H1N1 (or "swine flu”) pandemic of 2009-2010. The current pandemic of COVID-19 is spreading rapidly across all nations and its final impact is yet to be gauged as the pandemic is still continuing. The current COVID-19 pandemic is particularly deadly since many carriers are asymptomatic. It is estimated that $\sim 40 \%$ of those infected with SARSCoV-2 are asymptomatic and are responsible for spreading the infection. 
In general, most influenza outbreaks seem to be disproportionately lethal to the very young and elderly. The surprisingly higher than expected mortality during the flu pandemic of 1918 in young adults has been attributed to the triggering of a cytokine storm. Another explanation offered for the higher mortality in the young during this pandemic is to the superadded bacterial infection [14-16]. It is rather paradoxical to think that the strong immune reaction is harmful, whereas limited immune response of children and middle-aged adults is much less lethal.

\section{Structure of influenza virus}

The structure of the influenza virion is similar to SARS-CoV-2 and both are enveloped viruses (see Figure 2). It is important to understand the similarities and differences in the structure of influenza and SARS-CoV-2 viruses as given Table 1. These differences may underlie the variations seen between influenza-induced illness and SARS-CoV-2-induced severe illness in the form of ARDS (acute respiratory distress syndrome), cytokine storm and thrombosis of the lung capillaries and vessels, stroke, myocarditis and other features.

\section{COVID-19 and ACE2}

Even though COVID-19 is primarily a respiratory infection, it is now known that its manifestations may be seen in almost all systems of the body including cardiovascular and immune systems. Those who have pre-existing cardiovascular conditions are particularly vulnerable to disproportionately worse outcomes with almost 5-10-fold increase in mortality [17 $18]$.

There are many similarities between SARS-CoV-2 and SARS-CoV. SARs-CoV-2 and SARS-CoV spike proteins share $76.5 \%$ identity in amino acid sequences and their spike proteins have a high degree of homology [19-22]. It has been shown that residue 394 (glutamine) in the SARS-CoV-2 receptor-binding domain (RBD), corresponding to residue 479 in SARS-CoV, is recognized by the critical lysine 31 on the human ACE2 receptor [23]. SARS-CoV-2 recognizes and binds to human ACE2 more avidly compared to SARS-CoV [24-26]. It is known that blocking the renin-angiotensin pathway attenuates or at last reduces the severity of the lung 
damage due to SARS-CoV-2. This suggests that ACE2 is needed not only the virus to enter the target cell but also protects from lung injury.

$\mathrm{ACE}$ and its homologue ACE2 regulate the renin-angiotensin system. ACE cleaves the decapeptide angiotensin (Ang)I into the octapeptide AngII, whereas ACE2 cleaves a single residue from AngI to generate Ang 1-9 and a residue from AngII to generate Ang 1-7. Thus, ACE2 has a negative regulatory control on the renin-angiotensin system by inactivating AngII (see Figure 2). It is known that in ARDS (acute respiratory distress syndrome) there is a marked downregulation of ACE2 protein while ACE levels remained constant. ARDS can be improved by catalytically active ACE2. AngII levels in lungs and plasma are markedly increased in ARDS with a concomitant decreased ACE2 expression. Thus, ACE promotes ARDS through increased AngII production whereas ACE2 protects against ARDS [27]. In other words, inhibition of ACE activity may lead to decrease in the activity and receptor number of ACE-2 due to the feedback regulation that exists between ACE and ACE-2. The host cell entry of SARS-CoV-2 depends on the ACE2 receptor and can be blocked by inhibiting the cellular serine protease TMPRSS2 that is employed by SARS-CoV-2 for S protein priming.

\section{Clinical picture of COVID-19}

The most prominent and hallmark symptoms of COVID-19 are cough, fever, muscle aches, headaches and difficulty breathing that may lead to the development of ARDS necessitating some of these patients to be put on ventilator and ECMO (extracorporeal membrane oxygenation). It is estimated that about $20-30 \%$ of the patients put on ventilators eventually succumb to the disease [28-30]. In addition, some patients may have headache, dizziness, abdominal pain, diarrhea, nausea, and vomiting. With the onset of alveolar damage, these patients will have progressive respiratory failure that may lead to death (see Table 2 for common clinical features of COVID-19).

Since ACE2 is needed for host cell entry and subsequent viral replication, efforts have been made to study its expression and distribution in human body to know the potential infection routes of SARS-CoV-2. High ACE2 expression is seen in type II alveolar cells (AT2) of lung, esophagus upper and stratified epithelial cells, enterocytes from ileum and colon, cholangiocytes, 
myocardial cells, kidney proximal tubule cells, and bladder urothelial cells [31-33]. It is remarkable that ACE2 protein is present in various human organs including oral and nasal mucosa, nasopharynx, lung, stomach, small intestine, colon, skin, lymph nodes, thymus, bone marrow, spleen, liver, kidney, and brain. The expression of ACE2 protein on lung alveolar epithelial cells and enterocytes of the small intestine, vascular endothelial cells, and arterial smooth muscle cells of several organs may account for damage to these tissues during COVID19. This, in turn, may lead to the development of ARDS, thromboembolic manifestations and gastrointestinal disorders. The wide distribution of ACE2 in several human organs provides a clue as to the COVID-19 disease manifestations especially regarding the vascular complications such as thrombosis seen in peripheral blood vessels and in the smaller blood vessels of lungs.

Since several tissues contain high ACE2-expressing cells, they are potential sources through which SARS-CoV-2 can enter the body to produce its infection. In addition to these cells/tissues, another potential source of entry for the SARS-CoV-2 virus is the mucosa of oral cavity which has been shown to express ACE2 and are highly enriched in epithelial cells. Among different oral sites, ACE2 expression is highest in tongue than buccal and gingival tissues [33]. This observation lends support to the observation that SARS-CoV-2 can be shed by oral droplets and saliva and mucosa of oral cavity is a potential route of infection. Since many organs/tissues have the ACE2 receptor and SARS-CoV-2 is able to infect almost all tissues in the body, it is likely that SARS-CoV-2 can be found in the saliva, urine, feces, and other secretions. This is supported by the recent report that SARS-CoV-2 has been found in the sewage of several cities [34-37]. Hence, it is imperative that efforts should be made to see whether SARS-CoV-2 is present in all the urine, feces, and saliva in those who have been suspected to have the disease. This is important to know the source and route of infection to take suitable preventive measures to stop the spread of COVID-19. It is important to note that SARS-CoV-2 has been detected in municipal water supply and in sewage water, a possible source of infection. This assumes significance especially for third world countries (such as India) where the sewage and drinking water supply systems are not adequate. Since housing is inadequate and more than 5-6 persons live under one roof and washroom facilities are limited, the possibility of water source spread of COVID-19 is highly likely. This coupled with the lack of adequate facilities for testing (both RTPR and antibody) further aggravates the spread of COVID-19 in these countries. This is supported by the belief that in India with a population of almost 1.3 billion for one detected 
COVID-19 case there could be almost 300-400 undetected cases implying that there could be almost 300 million infected with SARS-CoV-2.

Some of the unusual manifestation of COVID-19 include anosmia and dysgeusia, skin rashes, diarrhea, kidney abnormalities and potentially life-threatening blood clots.

Anosmia (loss of sense of smell) and dysgeusia (alteration of sense of taste) are the most common early manifestation of COVID-19 that may go unnoticed, especially in the elderly. It was reported that anosmia could be present in $\sim 73 \%$ of patients much before COVID-19 diagnosis. Improvement in anosmia may occur in $\sim 27 \%$ of patients. The mean time to improvement was reported to be $\sim 7.2$ days whereas $85 \%$ showed improvement within 10 days [38]. These observations indicate that anosmia can be a presenting symptom of COVID-19. Anosmia may be critical to identify individuals infected with SARS-CoV2.

\section{Skin rashes and COVID toes}

Similar to many viral infections such as chicken pox or herpes, patients with COVID-19 also may show skin rashes that could be due to either direct invasion of the skin by the virus or as a result of immune reaction to the virus as seen in Epstein Barr Virus or West Nile infections. Some patients of COVID-19, especially children, show head-to-toe red rashes, hive-like eruptions, blister-like bubbles and even lacy, purply rashes spreading across larger patches of skin, and some are red, tender bumps that appear around the toes and heels-dubbed "COVID toes." It is suspected that those with lacy purple rashes are more likely to develop blood clots. Though it is no clear whether SARS-CoV-2 itself can cause rashes it is likely that the manifestations are as a result of an inert particle reaction in the skin, initiating an inflammatory process in response to circulating antibodies and sensitized lymphocytes. It is noteworthy that histological examination of the skin biopsy of these rashes showed that the findings are very much similar to hand-foot-and mouth disease and the RT-PCR for SARS-CoV-2 from the vesicles was negative. This negative reaction could be due to low viral load or absence of the virus itself. This suggests that contact with the skin rashes may not be infective [39]. 


\section{Gut manifestations}

Since intestinal epithelial cells are rich in ACE2, it is no wonder that gut is also a major target of SARS-CoV-2. Some of the gastrointestinal manifestations of COVID-19 include diarrhea, nausea and vomiting. It appears that those who had gastrointestinal symptoms tend to be diagnosed later and endure longer infections (partly because they are misdiagnosed with the mistaken belief that gut symptoms are unlikely due to COVID19). It needs to be emphasized that gut is a massive immune organ and so when they are infected it takes a long time to clear the virus from such a large organ. Since gut can get involved in COVID-19, it stands to reason that SARS-CoV-2 can be excreted in feces that itself could form a source of infection. Under normal conditions, the acid in the stomach is expected to inactivate the virus. Hence, use of antacids or proton pump inhibitors that suppress acid production may create a fertile ground for SARS-CoV-2 to proliferate and travel to the other parts of the gut. In contrast to this, it was reported that $\mathrm{H} 2$ blockers could be of benefit in COVID-19 [40, 41]. It has been proposed that SARS-CoV-2 may induce differentiation and activate mast cells. Such activated mast cells release histamine, proteases, cytokines, chemokines, and arachidonic acid derived prostaglandins (PGs) and leukotrienes (LTs) that have a role in inflammation. Histamine is known to be involved in the expression of chemokine IL-8 and cytokine IL-6, an effect that can be inhibited by $\mathrm{H} 2$ blockers. Alveolar macrophages activated by SARS-CoV-2 release IL-1 that, in turn, stimulates mast cells to produce IL-6. Both IL-1 and IL-6 can work together to produce excessive inflammation as seen in COVID-19. Furthermore, histamine enhances IL-1induced IL-6 gene expression and protein synthesis via $\mathrm{H} 2$ receptors in peripheral monocytes. Thus, histamine released by mast cells during inflammatory reaction as seen in COVID-19 can increase production of IL-1 to amplify inflammatory process in the lung infected with SARSCoV-2 [40]. This work is supported by the in silico work that showed that famotidine could interact with the catalytic site of the three proteases associated with SARS-CoV-2 and suggested that its intravenous administration could be of significant benefit in COVID-19 [41]. This proposal is supported by the observation that famotidine use was associated with a better

outcome in those with COVID-19 [42-44]. These initial observations need to be confirmed in a large-scale double-blind placebo controlled clinical trials. 


\section{Renovascular system}

The function of ACE in the kidney is to convert Ang I to Ang II to regulate blood pressure and salt and water balance (through aldosterone secretion modulation). Pulmonary epithelium is the main source of ACE. Intrarenal ACE production in the human kidney is about five times higher compared to ACE found in the human lung [45, 46]. A remarkably high concentration of $\mathrm{ACE}$ is present in the brush border of the proximal tubule, glomerular endothelium, mesangial cells, podocytes, and distal nephron [47-51]. The purpose of ACE2 enzyme is to counteracts many functions of the ACE (see Figure 2). ACE2 is needed to convert Ang II into the vasodilator and antiproliferative Ang 1-7 and Ang I into the inactive Ang 1-9. Ang 1-7 is an antioxidant, anti-fibrotic, and anti-inflammatory molecule, and acts through its receptor Mas (MasR) [52, 53]. ACE2 expression is also seen in heart, liver, lung, and neurons [54-56]. ACE2 expression is present in significant amounts in tubular and glomerular epithelium, vascular smooth muscle cells, the endothelium of interlobular arteries, and glomerular mesangial cells [57, 58]. SARSCoV-2 infection is seen in the kidney due to the presence of ACE2. SARS-CoV-2 can be detected in the urine of the infected people. Acute kidney injury among COVID-19 patients is seen in almost $\sim 36.6 \%$ of the patients admitted and some of them need dialysis [59, 60]. What is more important is the fact that those with renal injury due to COVID-19 could be correlated with severity of the respiratory symptoms. It is likely that SARS-CoV-2 can directly affect the kidneys and the resultant inflammatory response may worsen not only the respiratory involvement but also if there is any previous renal disease. The cytokines that are released as a result of SARS-CoV-2 infection can affect the blood vessels leading to renal ischemia that may worsen renal function necessitating appropriate interventions in the form of dialysis. This suggests that all those who have been diagnosed to have COVID-19 need to be assessed for their renal status and look for hematuria and urinary albumin presence, an indication of renal damage. But it is not yet clear whether COVID19 can cause any long-lasting renal damage and if so, what that could be.

\section{Hepatobiliary system}

Hepatocytes have ACE2 receptor and so are also target of SARS-CoV-2 infection. Further, more than half of the patients admitted for COVID-19 show alterations (higher 
or lower) in the levels of liver enzymes indicating that liver has been affected. But it is apparent that liver cell failure is unlikely and so hepatic functions are likely to reverse to normal over a period of time. The alterations seen in hepatic enzymes in COVI-19 could be due to either direct infection of hepatocytes by SARS-CoV-2 or secondary to inflammatory response seen in these patients. Lymphocytic infiltration associated with sinusoidal dilatation, steatosis, and multifocal hepatic necrosis can be seen in COVID-19 [61]. In the event these patients have pre-existing liver disease, it is likely to be exaggerated and may lead to further damage to liver in view of the inflammatory events associated with COVID-19.

\section{Thrombosis and its consequences in COID-19}

Vascular endothelial cells carry the ACE2 receptor, which implies that SARS-CoV2 can directly attack the blood vessels, especially of the lungs resulting in thrombosis in the pulmonary blood vessels (both venous and arterial) due to excessive inflammation, platelet activation, endothelial dysfunction, and stasis that contributes to ARDS seen in these patients. It is noteworthy that some patients with COVID-19, especially those who have severe disease, may have vascular thrombosis (due to endothelialitis) in the legs and lungs and sometimes these patient develop disseminated intravascular coagulation. This led to the suggestion that anti-thrombotic therapy may be of significant benefit to these patients.

These presumptions are supported by a recent study which showed that those who died from COVID-19 or influenza-associated respiratory failure showed diffuse alveolar damage with perivascular T-cell infiltration. COVID-19 specimens also showed severe endothelial injury with intracellular virus and disrupted cell membranes, whereas the pulmonary vessels revealed extensive thrombosis with microangiopathy and alveolar capillary microthrombi with an extremely high prevalence of intussusceptive angiogenesis compared to those with influenza. These results suggest that vascular angiogenesis pulmonary pathology of COVID-19 is distinctly different from that of equally severe influenza infection [62]. 
It has been reported that a remarkably high numbers of ACE2-positive cells are present in the lungs of those with Covid-19 compared to uninfected controls. Vascular endothelial cells are the main target of SARS-CoV-2 that can lead to disruption of intercellular junctions, cell swelling, and a loss of contact with the basal membrane. SARS-CoV-2 virus has been demonstrated within the endothelial cells suggesting that the virus has a direct effect on these cells (endothelial cells) that may be exaggerated by the perivascular inflammation noted [62]. Since many patients of COVID-19 recover completely even after ventilatory therapy, it can be assumed that several features described [62] are reversible though the time needed for this reversal to normal remains to be determined. It is also equally true that we still do not know whether all those who have recovered from COVID-19 have any residual pulmonary damage and if so, what are their long-term consequences. Nevertheless, the presence extensive capillary microthrombi in those with COVID-19 suggests that early institution of anti-coagulant therapy is warranted. Thrombosis of cerebral vessels leading to stroke is more common in young people suggesting that stroke in the young need to be assessed for the presence of SARS-CoV-2 infection. The big question is-does many, if not all, cases of stroke in the young need to be investigated for SARS-CoV-2 even during non-epidemic or non-pandemic period. One investigation that may help is the measurement of D-dimer in these patients. Similarly, coronary heart disease in the young with no known risk factors also need to be investigated for the presence of silent COVID-19 infection. This aspect needs special attention as almost $\sim 80 \%$ of the patients with SARS-CoV-2 infection are asymptomatic.

Another peculiar manifestation seen in COVID-19 is the complete lack of clot lysis at 30 minutes on a thromboelastogram (TEG) assay coupled with a D-dimer value above $2600 \mathrm{ng} / \mathrm{ml}$, indication that these patients need aggressive anticoagulation and many of them require mechanical ventilation, had acute renal failure requiring dialysis and some had thrombotic stroke. Other important abnormal laboratory investigations include elevated fibrinogen with normal platelet count, elevated prothrombin time and partial thromboplastin time. Many of these patients may also present cardiac abnormalities in the form of right heart failure, right ventricle dilatation, pulmonary thromboembolism and even after recovery from COVID-19. Some of these patients may continue to have palpitations and chest pain and MRI shows diffuse myocardial edema and fibrosis by late-gadolinium enhancement (LGE), or both along with impaired RV 
cardiac index and ejection fraction, despite preserved LV function. How long these abnormalities persist and whether it has any life-long consequences remain to be determined.

\section{Neurological manifestations}

In a retrospective study performed in 214 COVID-19 hospitalized patients in Wuhan, China it was reported that $\sim 37 \%$ showed some central neurological manifestations. Some of these include headache, dizziness, impaired consciousness, ataxia, epilepsy, and stroke. Of all, the most common manifestations have been headache and dizziness. Other manifestations include loss of taste and smell, neuralgia, and muscle pains, Guillain-Barre syndrome and some of these patients showed increase in plasma creatine kinase implying pathological involvement of muscles. Some patients even had stroke. It is not clear how many of these neurological manifestations are truly due to nervous system involvement or because of hypoxia. Nevertheless, they need to be considered as a part of the COVID-19 manifestations. These reported neurological manifestations reported from China have been confirmed from a study done in France. In order to document properly the possible involvement of nervous system in patients with COVID-19, detailed clinical, neurological and electrophysiological studies of these patients and efforts need to be made to isolate SARS-CoV-2 from cerebrospinal fluid, and autopsies of the COVID-19 patients need be carried out.

\section{COVID-19 in children}

Some disturbing findings reported in children needs special attention. It has been reported that children are uniquely susceptible to develop an acute cardiac decompensation due to severe inflammation following SARS-CoV-2 infection, termed multisystem inflammatory syndrome in children (MIS-C) [63-66]. Treatment with immunoglobulin seem to benefit these subjects with recovery of left ventricular systolic function. MIS-C has remarkably close similarities with Kawasaki disease. The data obtained so far indicates that these children present with cardiogenic shock, left ventricular dysfunction and severe inflammatory state. The mean ages of these patients is about 10 years, all had fever, $80 \%$ had gastrointestinal symptoms such as pain abdomen, vomiting and diarrhea and comorbidities such as higher body mass index (17\%), asthma (9\%), and lupus (3\%), and overweight. Only $17 \%$ presented with chest pain. 
Many of these patients had left ventricular ejection fraction that was less than $30 \%$, and $80 \%$ required inotropic support with $28 \%$ treated with extracorporeal membrane oxygenation (ECMO). All had severe inflammatory state as evidenced by elevated C-reactive protein and ddimer, higher plasma IL-6 elevated troponin, and NT-proBNP or BNP elevation. These patients are in need of IV inotropic support, IV immunoglobulin, anticoagulation with heparin, and received IV steroids.

\section{Current therapeutic approaches to COVID-19}

Several clinical trials are underway to know the efficacy of several drugs that could be useful either alone or in combination for COVID-19. Some of these include interferons, guanosine-analog RNA synthesis inhibitors, reverse transcriptase inhibitors or influenza drugs, Remdesivir, an antiviral. Some drugs are being investigated for their potential to block viral entry into the host cell (umifenovir, chloroquine or interferon), viral replication (lopinavir and ritonavir, ASC09 or darunavir/cobicistat) and viral RNA synthesis (inhibitors or influenza drugs, like remdesivir, favipiravir, emtricitabine/tenofovir alafenamide or ribavirin).

Since SARS-CoV-2 employs ACE2 and TMPRSS2 to enter target cells, attempts are being made to develop drugs that inhibit TMPRSS2. Janus-associated kinase (JAK) inhibitors that suppress inflammation are also being tested for their efficacy against COVID-19. Clinical trials are underway to use these drugs along with mesenchymal stem cells for COVID-19. These efforts will take time to know which of the strategies are likely to be successful. Several vaccines are under development for SARS-CoV-2 and are likely to take considerable time before they become available for the world's population. Furthermore, initial studies showed that those who developed COVID-19 do develop protective antibodies but whose titer seems to decline in about 3-6 months raising the possibility that even vaccine induced antibodies may not last long. It was also noted that some of the patients who recovered from COVID-19 have anti-interferon antibodies that may interfere with the anti-viral action of IFN (interferon) that seems to be more common in those who had severe COVID-19.

In view of these uncertainties and increasing incidence of mutations it is important to look at other novel and out of box methods of inactivating SARS-CoV-2 by understanding the 
natural mechanisms by which human body fights such infections. In the current narrative review, the potential role of bioactive lipids (BALs) in the pathobiology of COVD-19 is discussed based on their actions in the regulation of inflammation and immune response. Thus, the current study does not need ethical approval as it did not involve any interventions or studies in experimental animals or patients.

\section{Bioactive lipids inactivate enveloped viruses}

It is noteworthy that one of the unappreciated mechanisms by which many microbes can be inactivated by the human innate immune system is by elaboration of polyunsaturated fatty acids (PUFAs) and their metabolites (termed as bioactive lipids). Several bioactive lipids especially linoleic acid (LA), gamma-linolenic acid (GLA), dihomo-GLA (DGLA), arachidonic acid (AA), alpha-linolenic acid (ALA), eicosapentaenoic acid (EPA) and docosahexaenoic acid (DHA) can inactivate Streptococci, Staphylococci, both gram-positive and gram-negative bacteria, fungi and enveloped viruses, including influenza, HCV, HBV and HIV [67-75]. These fatty acids disrupt the microbial cell membranes, interfere with the cellular metabolic processes including inhibition of respiratory activity, transportation of amino acids, and uncoupling of oxidative phosphorylation. Based on these evidences [67-75], it is reasonable to propose that alveolar macrophages, leukocytes, T and B cells, NK cells and other immunocytes release AA and other unsaturated fatty acids to inactive various microbes including SARS-CoV-2, SARS, and MERS. It is possible that human body protects itself from various microbes using these unsaturated fatty acids. Based on these observations, it can be suggested that a deficiency of AA and other unsaturated fatty acids can predispose an individual susceptible to various infections including SARS-CoV-2, SARS, and MERS. Alveolar macrophages can secrete AA and other unsaturated fatty acids into the alveolar fluid to inactivate SARS-CoV-2, SARS and MERS and several other bacteria and fungi [76-92]. This implies that administration of these fatty acids could be of significant benefit against SARS-CoV-2, SARS, and MERS.

\section{Phospholipase A2 (PLA2) is microbicidal in nature}

Type-IIA secreted phospholipase A2 (sPLA(2)-IIA) releases AA and other unsaturated fatty acids from the cell membrane phospholipid pool, a mechanism developed by various cells 
including immunocytes to fight against microbes. It is noteworthy that sPLA2-IIA present in animal and human biological fluids is sufficient to bring about its antimicrobial action. Human recombinant sPLA2-IIA induced release of PUFAs in response to several bacteria and viruses at concentrations $\sim 1.1 \mathrm{ng} / \mathrm{ml}$ that prefers anionic phospholipids such as phosphatidylglycerol, which is the main phospholipid component of bacterial membranes. In contrast to this, higher concentrations of sPLA2-IIA are needed to act on the host cell membranes and surfactant both of which are mainly composed of phosphatidylcholine that is a poor substrate for sPLA2-IIA. It is noteworthy that over-expression of human sPLA2-IIA renders cells resistant to Staphylococcus aureus, Escherichia coli, and Bacillus anthracis infections. Furthermore, intranasal administration of sPLA2-IIA protects mice from microbial infections including pulmonary anthrax, implying that this mode of administration of sPLA2-IIA and PUFAs could be employed to protect against SARS-CoV-2, SARS, and MERS [93-96]. In a similar fashion, even bioactive lipids can be administered intranasally to prevent various microbial infections including SARSCoV-2, SARS, and MERS.

Bioactive lipids (BALs) including AA mediate the antimicrobial action of macrophages

Humans are constantly exposed to various microbes through inhaled air that calls for an efficient and simple mechanism(s) to prevent and protect lungs from various infections. In other words, alveolar macrophages need to possess an efficient mechanism to prevent microbial infections. Inhaled staphylococci can be eliminated by alveolar macrophages utilizing AA and other bioactive lipids derived from the extracellular fluid and thus, protect lungs from the invading microbes. Even immunocytes may protect various tissues from microbial infections in the same fashion [72, 93, 94, 98-108] (see Figures 3A and 3B for metabolism of essential fatty acids and their role in inflammation and restoration of homeostasis and their role in COVID-19). This is supported by the observation that lymphokine-activated macrophages release bioactive lipids to induce apoptosis of tumor cells [107]. Thus, alveolar lining material interacts with alveolar macrophages, whereas tumor cells interact with microenvironment that is tuned to the benefit of the body. Proliferation of tumor cells can be inhibited by the immunocytes present in the tumor microenvironment by secreting bioactive lipids. Even normal cells surrounding the tumor cells can secrete bioactive lipids in order to restrain tumor cell growth. At the same time, it is possible that tumor cells may take advantage of the secreted bioactive lipids especially GLA, 
DGLA, AA, EPA and DHA to form PGE2/PGE3 and leukotrienes that possess immunosuppressive actions. Thus, there may be an intense competition between normal cells/immunocytes and tumor cells for the secreted bioactive lipids. The outcome (tumor cell growth or tumor cell apoptosis) of this competition depends on the way the released GLA/DGLA/AA/EPA/DHA (by the normal cells) are metabolized by normal and tumor cells. If the normal cells are able to dominate and produce lipoxins, resolvins, protectins and maresins by utilizing these fatty acids (GLA/DGLA/AA/EPA/DHA) and enhance NO and ROS generation then the tumor cells are induced to undergo apoptosis or remain dormant for a long time. In contrast, if tumor cells are able to uptake these fatty acids to convert them to PGE2/PGE3/LTs and inhibit or decrease the formation/production of lipoxins, resolvins, protectins and maresins by normal cells (since the surrounding immunocytes or normal cells are unable to have access to $\mathrm{AA} / \mathrm{EPA} / \mathrm{DHA})$, then the tumor cells will be able to induce immunosuppression and proliferate (see Figure 4).

\section{Crosstalk between microbes and host cells/tissues}

Similarly, there could occur a crosstalk between the invading microorganisms and the host tissue/cells to utilize GLA/DGLA/AA/EPA/DHA secreted by normal cells/target cells (including $\mathrm{T}$ cells and $\mathrm{NK}$ cells) and the microbes. Microbes are known to influence the metabolism of GLA/DGLA/AA/EPA/DHA by target cells to form PGE2/PGE3/LTs to produce local inflammation and immunosuppression. On the other hand, the host tissues/cells and immunocytes utilize these fatty acids to inactivate microbes by producing lipid peroxides, NO, and regulating the production of IL-6, TNF- $\alpha$ and IFN and other anti-microbial cytokines/products. This is supported by the observation that (i) some bacteria can induce activation of the inflammatory signalling pathway [109]; (ii) COX-2 expression was increased in macrophages infected with the wild-type colon cancer-associated E. coli 11G5 strain but not by a clbQ mutant, indicating that tumor- infiltrating bacteria induce the expression of COX-2 to enable the tumor cells and tumor infiltrating macrophages to produce PGE2, a immunosuppressor [110]; (iii) heat-killed Mycobacterium can downregulate MMP-9 in murine peritoneal macrophages through COX-2 and independent of TNF- $\alpha$ [111] suggesting that immunosuppression seen in the host during tuberculosis infection is due to local production of PGE2; and finally, (iv) COX-2 can be induced by CMV (cytomegalovirus) in human RPE cells that can lead to translocation of the induced NF-kB from the cytoplasm to the nucleus associated 
with an increase in the production of PGE1 and PGE2 in these cells that significantly increased CMV proliferation [112]. Since, under physiological conditions, there is a balance maintained between pro-inflammatory PGE2 and anti-inflammatory lipoxins, resolvins, protectins and maresins it is reasonable to suggest that these anti-inflammatory bioactive lipids inhibit viral replication (similar to GLA/DGLA/AA/EPA/DHA). These studies lend support to the concept that microbes (and in a similar fashion tumor cells) enhance the expression of COX-2 and other enzymes of the PG pathway in the host cell and thus, alter the balance between pro-inflammatory and anti-inflammatory bioactive lipids at the site of infection or tumor invasion. This, in turn, alters the host response to tumor cells or infection by the invading microbes (including viruses such as SARS-CoV-2). It is possible, but yet to be verified, that tumor cells can upsurge the COX2-LOX pathway of the normal cells in the tumor microenvironment for their benefit. In a similar fashion, certain bacteria (such as Lactobacilli) may support the host tissues to overcome microbial resistance by modulating host COX-LOX enzymes [113, 114].

\section{Immunocytes release bioactive lipids (BALs)}

Immunocytes (NK cells, cytotoxic tumor lymphocytes: CTL cells, lymphokine activated killer cells, dendritic cells, leukocytes, etc.,) release perforin and granzyme, cytokines IL-6, TNF$\alpha$, and IFN- $\gamma$ to eliminate tumor and infected cells. Surprisingly, NK cells and CTLs induce tumor cell apoptosis even in the absence of perforin and granzyme by enhancing the expression of soluble PLA2 (sPLA2) [115]. PLD (phospholipase D) activation that leads to release of AA is needed for the CD16-triggered signaling cascade to induce exocytosis of the NK cytotoxic granules $[116,117]$. It is noteworthy that lipids form a constitutive component of cytolytic granules of CTL, NK and $\gamma \delta$ T cells [118] and cytokine-activated macrophages (and probably other immunocytes) can release bioactive lipids to induce apoptosis of tumor cells [107, 119121]. These results emphasize the importance of PLA2/PLD and release of bioactive lipids for the cytolytic action and release of cytolytic granules by immunocytes.

It is noteworthy that macrophages and tissue-resident memory CD8 $+\mathrm{T}$ cells cooperate with each other to sense pathogens and protect the barrier tissues [122]. This is somewhat akin to the crosstalk/interaction seen between alveolar lining material and macrophages to eliminate invading microbes and tumor cells [100]. A close cooperation/interaction exists between epithelial cells and macrophages that is similar to the interaction between tissue resident memory 
T cells and their surrounding milieu. The resident memory $\mathrm{T}$ cells are dependent on fatty acids for their survival and function. These much-needed fatty acids are transported to the $\mathrm{T}$ cells by the specific fatty acid binding protein (FABP). The type of FABP expressed by the $\mathrm{T}$ cells depends on the tissue in which they are resident implying that the tissue resident memory $\mathrm{T}$ cells show varying patterns of FABP isoform usage that, in turn, is determined by tissue-derived factors. To meet the fatty acid demands of the tissue resident memory $\mathrm{T}$ cells (and other immunocytes including macrophages), these cells modify their FABP expression depending on the tissue in which they are located or relocated [123]. This suggests that each tissue and their resident memory $\mathrm{T}$ cells (and macrophages and other immunocytes) need to get a specific type(s) of bioactive lipid(s) not only for their survival but also to bring about their specific action(s) that is tailored to their location as dictated by the local milieu. In an extension of this argument, it can be postulated that to inactivate a specific type of invading microbes (including viruses) a specific type or types of bioactive lipid(s) is needed that, in turn, depends on the target tissue.

Macrophages can be either M1 or M2 type. M1 type macrophages have pro-inflammatory actions whereas M2 is anti-inflammatory in nature (see Figure 5). M1 are needed to kill the invading microbes including SARS-CoV2 and clear the debris. Once the much-needed inflammatory process is completed and invading microbes are cleared, $\mathrm{M} 2$ are needed to induce resolution of inflammation and restore homeostasis. PGE2 and leukotrienes are needed for the generation of M1 macrophages and they (M1) generate these pro-inflammatory PGE2 and leukotrienes. In contrast, anti-inflammatory cytokines and lipoxin A4 (LXA4) from AA, resolvins from eicosapentaenoic acid (EPA) and docosahexaenoic acid (DHA) and protectins and maresins from DHA facilitate generation of M2 macrophages and induce resolution of inflammation restore homeostasis [73, 124-136]. But there is one caveat for this process of inflammation to anti-inflammation or resolution of inflammation to occur in a coordinated, smooth and orderly fashion, which is the availability of GLA/DGLA/AA/EPA/DHA in adequate amounts at the right time and at the right place. Any discrepancy in this sequence of events may result in acute inflammatory process to become chronic and failure of resolution. For this smooth transition from pro-inflammatory events to resolution of inflammation and restoration of homeostasis needs adequate activity of desaturases, COX and LOX enzymes (including soluble epoxy hydrolase: sEH), PGDH, an appropriate balance between pro- and anti-inflammatory cytokines, generation of adequate amounts of ROS, NO, CO, H2S and sufficient activity of various antioxidants. These enzymes, free radicals and antioxidants are needed to regulate oxidative and 
mitochondrial stress and to regulate the actions of leukocytes, macrophages, T cells, NK cells and CT cells and to process a smooth and timely communication(s) between various immunocytes, host cells/tissues and the invading microbes (including SARS-CoV-2). Any hindrance in any one of these process will result in exacerbation of the clinical picture of COVID19 and lead to the onset of its complications.

In this context, the relationship between pro-inflammatory cytokines and EFA metabolism needs a closer look. Both TNF- $\alpha$ and IL-6 can block the activities of desaturases which are needed for the conversion of dietary linoleic acid (LA) and alpha-linolenic acid (ALA) to their respective long-chain metabolites namely AA and EPA and DHA respectively [137]. This could be the reason as to why patients with rheumatoid arthritis, lupus, and sepsis have low plasma concentrations of AA, EPA and DHA [138-141]. As a consequence of this precursor (GLA, DGLA, AA, EPA and DHA) deficiency, the generation of LXA4, resolvins, protectins and maresins that are potent inhibitors of IL-6 and TNF- $\alpha$ formation is insufficient. Hence it is predicted that patients with COVID-19 will have deficiency of GLA/DGLA/AA/EPA/DHA and LXA4/maresins, resolvins/protectins. These results indicate that administration of GLA/DGLA/AA/EPA/DHA/PGE1/LXA4, resolvins, protectins and maresins will be of significant benefit in COVID-19 by (i) suppressing inappropriate production of IL-6 and TNF$\alpha$, (ii) ameliorating inflammation and excess pro-inflammatory cytokine storm, (iii) protecting normal cells (especially bone marrow cells, myocardial cells, hepatic and renal tissues) and thus, initiate recovery [142-155].

\section{Bioactive lipids and M1 and M2 macrophages}

Once the inflammatory process has achieved its function of eliminating the invading microbes (including SARSoCoV-2) and debris removal is completed by the M1 type, macrophages change their phenotype to $\mathrm{M} 2$ type to initiate resolution of inflammatory process by producing anti-inflammatory cytokines and anti-inflammatory bioactive lipids such as lipoxin A4 (LXA4) from AA, resolvins from eicosapentaenoic acid (EPA) and docosahexaenoic acid (DHA) and protectins and maresins from DHA [156-169]. These results imply that proinflammatory bioactive lipids induce the M1 phenotype whereas anti-inflammatory bioactive lipids trigger the generation of $\mathrm{M} 2$ macrophage phenotype. These studies suggest that the way GLA/DGLA/AA/EPA/DHA are metabolized by the macrophages and their modulation by the 
pro- and anti-inflammatory cytokines, changes in the activities of desaturases, cyclo-oxygenase2 (COX-2) and LOX (5-, 12-, and 15-lipoxygenases) determines the shift in the balance between M1 and M2 macrophages [156-169]. Thus, generation of adequate concentrations of GLA/DGLA/AA/EPA/DHA and their conversion to PGE1, LXA4, resolvins, protectins and maresins by the appropriate concentrations and action of desaturases, COX-2, 5-, 12-, and 15LOX and 15-PGDH results in the generation of $\mathrm{M} 1$ and $\mathrm{M} 2$ macrophages as the situation demands. When the adequate amounts of IL-6 and TNF- $\alpha$ and other pro-inflammatory cytokines are generated in the initial stages of infection due to SARS-CoV-2 (and other enveloped viruses and microbes) and formation of PGE2 occurs in adequate amounts it leads to the generation of M1 macrophages, whereas generation of $\mathrm{M}_{2}$ type occurs when $\mathrm{PGE} 1 / \mathrm{LXA} 4 /$ resolvins/protectins/maresins are formed in appropriate amounts at the time of resolution of inflammation [156-169]. Though this argument looks apparently simple and straight forward, it is not known how exactly this shift of balance from pro- to anti-inflammatory pathway and M1 to M2 phenotype occurs is not clear. In this shift of balance from pro- to antiinflammatory pathway and maintenance of balance between M1 and M2 macrophages, there seems to be a critical role for $\mathrm{NO} / \mathrm{CO} / \mathrm{H} 2 \mathrm{~S}$ (nitric oxide/carbon monoxide/hydrogen sulfide) that have an important role in the acceleration of resolution of inflammation and tissue regeneration. This balance between pro- and anti-inflammatory status and M1 and M2 macrophages and factors that could be involved in their formation and action are critical for fighting viral infections HCV, HBV, SARS-CoV-2, SARS and MERS and restore homeostasis by inducing necessary tissue repair and regeneration and resolution of inflammation (see Figures $3 \mathrm{~B}, 4,5$, and $6 \mathrm{~A})$.

\section{Interaction between PGE2 and LXA4}

Despite the fact that, in general, PGE2 is considered as a pro-inflammatory bioactive lipid, studies did suggest that this prostaglandin can also have anti-inflammatory and immunosuppressive actions [170-176], especially, by altering macrophage polarization by MSCs (mesenchymal stem cells) [177-179]. This pro- and anti-inflammatory actions of PGE2 seem to depend on its binding to different types of PGE2 receptors (EPs) that is concentration dependent. At low concentrations, PGE2 binds to the high-affinity EP4 receptor and enhances IL-23 production [180], whereas high PGE2 amounts bind to $\mathrm{EP} 2$ receptor and suppresses IL-23 release $[181,182]$. These results account for the dual pro and anti-inflammatory actions of PGE2 
[183]. Furthermore, PGE2 can induce LXA4 and suppress LTB4 production by modulating 5and 15-lipoxygenase expression and thus, enable pro-inflammatory status to be switched over to anti-inflammatory pathway (see Figure 7). This switchover from pro-inflammatory (LTB4) pathway to the anti-inflammatory pathway (LXA4) enables the removal of neutrophils from the site of inflammation and help in the resolution of inflammation [182-184]. This crosstalk between macrophages and neutrophil on one hand and PGE2 and LXA4 on the other enables induction of resolution of inflammation that is critical to dampen inflammation. This redirection of the formation of $\mathrm{PGE} 2$ from AA to LXA4 to induce resolution of inflammation seems to depend on the biphasic release of AA from the cell membrane lipid pool. The first pulse of release of AA occurs due to the activation of iPLA2 (calcium independent phospholipase A2) that is utilized for the formation of PGE2 whereas the second phase of release of AA due to the activation of cPLA2 (cytosolic phospholipase A2) and sPLA2 (secreted phospholipase A2) is utilized for the formation of LXA4 (see Figures 5-7). This implies that the cell has the unique ability to direct AA released by iPLA2 to form PGE2 and cPLA2 and sPLA2 induced release of AA for the formation of LXA4. It is not clear whether other PGEs also have actions similar to PGE2. For instance, PGE1, derived from DGLA, is an anti-inflammatory, vasodilator, and platelet antiaggregator, whose actions are remarkably similar to those of LXA4. It is likely that PGE1 may also enhance the formation of LXA4. But this needs to be confirmed.

\section{PGE2 augments tissue regeneration}

It is evident from these results [161-184] that once the inflammation and the concentrations of PGE2 reach a peak, AA released from the cell membrane lipid pool is redirected to form LXA4 instead of PGE2 (see Figures 3B, 4 and 7). This redirection of AA metabolism from PGE2 to LXA4 is an essential step needed to induce resolution of inflammation [156, 183185]. This attainment of PGE2 concentration to peak not only initiates LXA4 synthesis but also triggers simultaneously tissue regeneration. This is supported by the report that 15-PGDH-(15prostaglandin dehydrogenase, a prostaglandin degrading enzyme) deficient mice not only have a twofold increase in bone marrow, colon, and liver PGE2 levels but also showed increased fitness of these tissues with augmented hematopoietic capacity. These 15-PGDH deficient animals showed a rapid liver regeneration after partial hepatectomy and enhanced recovery of neutrophils, platelets, and erythrocytes [185] Several other studies are in support of this observation that PGE2 promotes hematopoiesis [186-189]. Thus, administration of PGE2, 
LXA4, AA, EPA and DHA, resolvins, protectins and maresins, which are potent inhibitors of IL$6, \mathrm{TNF}-\alpha$ and other pro-inflammatory cytokines $[154-156,182,183]$ are expected to be of significant benefit in COVID-19. It is predicted that administration of appropriate amounts and in a timely manner of AA/PGE2/LXA4 and other bioactive lipids not only inactivate SARSCoV-2 virus $[117,133,135,156,163,190,191]$ but can prevent or even reverse inappropriate activation of coagulation, microvascular thrombosis and consumption of coagulation factors seen in those with severe COVID-19 and suppress cytokine storm [183, 191].

\section{LXA4 mediates MSCs (mesenchymal stem cells) resolution of inflammation}

It has been demonstrated that bone marrow derived MSCs can reduce the severity of acute lung injury by secreting LXA4, whereas blocking LXA4 receptor reversed this protective action. Furthermore, LXA4 by itself has been shown to suppress LPS-induced acute lung injury in experimental animals by decreasing the production of TNF- $\alpha$ and MIP-2. Both human alveolar epithelial type II cells and MSCs express biosynthetic enzymes and receptors for LXA4 $[192,193]$. These results coupled with the observation that MSCs are effective in the treatment of diabetic nephropathy by secreting LXA4 that, in turn, downregulates TNF- $\alpha$, IL-6, IL-8, and IFN- $\gamma$ [194]. This may explain the beneficial action of MSCs reported in COVID-19 [195].

In addition, targeted PGE2 suppression has been shown to significantly improve survival against lethal influenza infection, whereas PGE2 administration enhanced mortality [196]. These results can be interpreted to indicate that when PGE2 synthesis is blocked in a specific fashion, there will be an increase in LXA4 synthesis since both PGE2 and LXA4 are derived from the same precursor AA that, in turn, is responsible for the beneficial action of inhibition of PGE2 pathway and thus, an increase in LXA4 formation is of benefit in the influenza and COVID-19 (see Figures 3B, 4, 6, 7). It is noteworthy that AA can also be metabolized by cytochrome $\mathrm{P} 450$ set of enzymes to form a variety of epoxyeicosatrienoic acids (EETs) that are also known to possess anti-inflammatory action. EETs are degraded by soluble epoxy hydrolase $(\mathrm{sEH})$ and hence, inhibition of sEH will enhance their half-life and thus, their beneficial actions can be augmented. It is interesting to note that LXA4 inhibits the activity of sEH and supplementation of ALA (and possibly other fatty acids such as AA/EPA/DHA) has been shown to inhibit the activity of $\mathrm{sEH}$ [197, 198]. These results suggest that AA/EPA/DHA/LXA4/resolvins/protectins and maresins inhibit sEH activity and ultimately 
enhance the concentrations of LXA4/resolvins/protectins/maresins and possibly, inhibit excess production of PGE2 and thus suppress inflammatory events seen in COVID-19 (see Figures 3B, $4,6,7)$.

\section{Increased mortality due to COVID-19 in those with co-morbid conditions and BALs}

It is known that those who have obesity, type 2 diabetes mellitus, hypertension, and coronary heart disease and even otherwise elderly have a degree of mortality if they get COVID19. The exact cause of this is not clear. Previously, we showed that plasma levels of $\mathrm{AA} / \mathrm{EPA} / \mathrm{DHA}$ are low in these diseases suggesting that the activities of desaturases are defective or decreased leading to a deficiency of AA/EPA.DHA in them [199]. In addition, these fatty acids are needed to maintain normal cell membrane fluidity and integrity. Hence, AA/EPA/DHA deficiency will lead to alterations in the expression of ACE2 and SARS-CoV-2 cannot be inactivated by BALs (since their concentrations are below the physiological optimum levels) leading to an increase in the virulence of the virus. AA/EPA/DHA deficiency induced alterations in the cell membrane fluidity may enhance the binding of SARS-CoV-2 to ACE-2. This is supported by the recent report that SARS-CoV-2 spike (S) receptor binding domains (RBDs) tightly bind the essential free fatty acid (EFA) linoleic acid (LA) in three composite binding pockets. LA binding appears to stabilize a locked $\mathrm{S}$ conformation that results in reduced ACE2 interaction in vitro. In human cells, LA supplementation synergized with the COVID-19 drug remdesivir and suppressed SARS-CoV-2 replication [200]. It is likely that other PUFAs such as GLA, DGLA, AA, EPA and DHA may have similar properties and thus, selectively inhibit the binding of SARS-COV-2 to ACE2 and inhibit viral replication as suggested previously [156, 183, 190, 191]. In such a scenario, deficiency of AA/EPA/DHA will also result in decreased formation of LXA4/resolvins/protectins/maresins and as a result the inflammatory process triggered by SARS-CoV-2 will flourish leading to cytokine storm.

Several studies suggested that children are unlikely to have severe COVID-19 and even if they develop the disease it is rather mild unlike in elderly who may have cytokine storm and consequently higher degree of mortality. This discrepancy in the clinical picture and mortality due to COVID-19 remains unexplained that can also be attributed to BALs. It is known that with increasing age there is a decrease in the activity of desaturases. Thus, elderly will have low activity of delta-6-desaturase and delta-5desaturase and so have a decrease in the plasma levels 
of GLA/DGLA/AA/EPA/DHA. In addition, with increasing age there is a fall in the plasma circulating levels of LXA4 [201]. Thus, deficiencies of AA/EPA/DHA and LXA4 and low activities of desaturases may account for severe COVID-19 seen in the elderly and those with other co-morbid conditions. This could be rectified to a large extent by supplementation of $\mathrm{AA} / \mathrm{EPA} / \mathrm{DHA}$. This is supported by the observation that supplementation/administration of AA does not increase the formation of PGE2 and inflammatory process and in fact, may suppress inflammation [202-204]. AA can be given both orally and intravenously without any significant side effects and is safe to normal healthy subjects [205].

Young children are unlikely to have significant COVID-19 disease since they have high activity of desaturases and are able to form significant amounts of AA/EPA/DHA/LXA4 when needed (see Figure 6). The robustness of the desaturase-PLA2-BALs pathway in the children may render them less susceptible to the cytokine storm and COVID-19 infection and when this system fails, they may develop systemic multi-system inflammatory syndrome characterized by myocarditis, ARDS, and other features described in them.

\section{Conclusions and therapeutic implications}

It is evident from the preceding discussion that AA and other PUFAs can potentially inactivate SARS-CoV-2, SARS, MERS, HCV, HBV, and influenza viruses. Of all the unsaturated fatty acids, perhaps AA $(\mathrm{AA}>\mathrm{EPA}=\mathrm{DHA})$ is the most potent in this ability. Studies suggested that AA need to undergo peroxidation to inactivate $\mathrm{HCV}$ and $\mathrm{HBV}$ since vitamin $\mathrm{E}$ that interferes with its (AA) peroxidation abrogated its (AA) anti-viral action [73-75, 157, 182].

Inflammatory events triggered by microbes including SARS-CoV-2 results in excess production of IL-6 and TNF- $\alpha$ and PGE2 and LTs by leukocytes, macrophages, T cells and the target tissues that can be suppressed by BALs GLA/DGLA/AA/EPA/DHA and their metabolites LXA4, resolvins, protectins and maresins. Thus, both inactivation of enveloped viruses and suppressing the associated inflammatory events is achieved by these BALs in association with anti-inflammatory cytokines. This implies that a delicate balance normally exists between pro and anti-inflammatory events and molecules involved in these processes that ultimately determines recovery and restoration of homeostasis. In addition, BALs also can regulate the plasticity of macrophages to enable them to switch from M1 to M2 phenotype (or 
vice versa) (see Figure 5). Based on these evidences, it is reasonable to propose that administration of AA/EPA/DHA could be of significant benefit in SARS-CoV-2, SARS, and MERS (and in HCV and HBV and influenza) infections. These PUFAs could be administered orally and/or intravenously without any significant side effects. It is not unreasonable to suggest that suitable preparations of PUFAs could be prepared for their intranasal administration.

Recent studies did suggest that formation of neutrophil extracellular traps (NETs)-may contribute to organ damage and mortality in COVID-19 [206]. It is noteworthy that NETs formation can be modulated (enhance or suppress their formation as the situation demands) by LXA4/resolvins/protectins/maresins [207-210], yet another mechanism by which BALs are of potential therapeutic benefit in COVID-19. BALs are also capable of inhibiting janus kinase (JAK) and thus, may bring about their beneficial action in COVID-19 [211-214]. Thus, BALs have several actions that attest to the fact that they are of benefit in COVID-19. In addition, corticosteroids are known to inhibit the activities of PLA2, desaturases, COX-2 and LOX enzymes and thus, may bring about their immunosuppressive action, at least, in part by inhibiting the formation of PGE2. It is paradoxical that corticosteroids inhibit the formation of LXA4 > LTB4 that may explain why steroids interfere with the resolution of inflammation and wound healing process. Thus, continued use of corticosteroids results in an EFA deficiency state and leads to decreased formation of LXA4, resolvins, protectins and maresins. This may explain why dexamethasone is beneficial only in mild to moderately severe COVID-19 but not those who are critically ill. The more critically ill with COVID-19 are expected to have an EFA deficiency state and hence, are unlikely to respond since they do not have adequate cellular/plasma content of AA/EPA/DHA to form appropriate amounts of PGE2 and LXA4 to resolve inflammation and augment wound healing [117, 133-136]. This may explain as to why those with COVID-19 who have high levels of cortisol on admission to hospital have a substantially increased risk of dying [215] since they are more likely to have high degree of EFA deficiency state. Hence, if these patients are supplemented with BALs along with other treatment options are expected to respond favorably.

It is worth noting that glucocorticoids in addition to inhibiting the expression of PLA2, COX-2, LOX, and desaturases enhance the expression of annexin-1 also called as lipocortin 1. Annexin-1 shows all the actions of glucocorticoids and induces anti-inflammatory cytokine IL10. Annexin-1 suppresses the expression of TNF- $\alpha$, IL-6, and other cytokines [216]. For the 
anti-inflammatory action of annexin-1, there is an essential role for LXA4. Both LXA4 and/or annexin-1 seem to enhance the production of IL-10, which suppresses TNF- $\alpha$ action and the consequent tissue injury and lethality [217]. Thus, there is a complex and inter-dependent interaction among PLA2, COX-2, desaturases, annexin-1 and LXA4 in the anti-inflammatory action of corticosteroids.

The recent observation that patients who took statins are likely to have much reduced mortality rate $[218,219]$ can be related to their action on EFA metabolism [220- 223]. Statins are known to enhance th formation of AA and LXA4 and thus, bring about their beneficial actions. This action of stains on the bioactive lipids is one of the reasons for their antiinflammatory action. Similarly, the less frequent and mild disease seen in children and decreased incidence of COVID-19 in women can also be ascribed to BALs. For instance, the activity of desaturases decreases with age (see Figure 6B), whereas estrogen stimulates LXA4 synthesis [224, 225]. Thus, it is anticipated that children have a higher capacity to generate GLA, DGLA, AA, EPA and DHA that can be converted to form beneficial LXA4, resolvins, protectins and maresins to fight SARS-CoV-2. On the other hand, pre-menopausal women generate significantly higher amounts of LXA4 due to the stimulatory action of estrogen and thus, are resistant and less likely to develop severe COVID-19. Similarly, even the beneficial action of blocking GM-CSF and administration of colchicine in COVID-19 can be related to their ability to modulate BALs [226-230]. The property of colchicine to potentiate the actions of PGE1 is especially interesting since both PGE1 and LXA4 have similar actions.

A recent study reported that circulating levels of IL-2, IL-4, TNF- $\alpha$, IFN- $\gamma$ and Creactive protein are not associated with severity of COVID-19 symptoms. This indicates that there could be two phases in the pathobiology of COVID-19, one phase characterized by hyperinflammation in the beginning of the disease and another phase of immunosuppression with little or no changes in the pro-inflammatory cytokines as seen in sepsis [231-233]. If this is true, then it will be hazardous to administer dexamethasone, anti-cytokine and other immunosuppressive therapies during the immunosuppressive phase of COVID-19. Hence, one need to exercise caution in rushing to administer immunosuppressive therapies without measuring plasma cytokines levels and viral load (see Figures 8 and 9). 
It was reported that $\mathrm{H} 2$ blockers such as famotidine could be of significant benefit in those who are admitted with COVID-19 [234, 235]. Those who have taken famotidine were found to have better outcome. The exact cause for this benefit is not clear. Famotidine could inhibit 3chymotrypsin-like protease, the enzyme that processes proteins essential for viral replication. At this juncture, it is noteworthy that famotidine enhances AA formation and thus, augments duodenal ulcer healing. Patients with peptic ulcer have low plasma concentrations of AA that reverted to normal following famotidine, fish oil and ARASCO oil (AA rich oil) treatments [236238]. These results emphasize the importance of AA and other BALs in the pathobiology of peptic ulcer disease and their role in wound healing. It is also significant to know that Helicobacter Pylori, the organism that is responsible for peptic ulceration, can be inhibited by BALs [239-240] that is in tune with the anti-microbial action of BALs.

Impaired interferon (IFN) type I response in the form of no IFN- $\beta$ and low IFN- $\alpha$ production and activity was described in those with severe COVID-19 associated with a persistent blood viral load (SARS-CoV-2) and an exacerbated inflammatory response. In these patients, inflammation was found to be driven by upregulation of $\mathrm{NF}-\kappa \mathrm{B}$ and enhanced production of TNF- $\alpha$ and IL-6 [241, 242]. These data imply that type I IFN deficiency could be a hallmark of severe COVID-19 suggesting that IFN therapy is indicated in these patients. This is supported by the observation that severe COVID-19 is associated with impaired $\mathrm{T}$ cell responses in the form of lymphopenia and functional exhaustion of $\mathrm{CD} 4^{+}$and $\mathrm{CD} 8^{+} \mathrm{T}$ cells possibly, due to deficient IFN production. Furthermore, deficient, or dysregulated IFN responses observed in SARS-CoV-2 infection may influence the generation of $\mathrm{T}_{\text {reg }}$ cells during the recovery phase of COVID-19.

TNF- $\alpha$ and IL-6 enhance PGE2 and thus, may indirectly suppress LXA4 concentrations, whereas both PGE2 and LXA4 and their precursor AA decrease TNF- $\alpha$, IL-6 and IFN production $[154,155,243-245]$. IFN seems to bring about its actions by activating phospholipase C, D and A2 to induce the release of AA (and possibly GLA, DGLA, EPA and DHA) that can be converted to PGE2 and LXA4 [246-248]. PGE2, LXA4, AA, EPA and DHA are potent inhibitors of IFN production [249-254] and IFN can both enhance and decrease PGE2 synthesis depending on the context [255, 256]. These results could be interpreted to imply that if the production of IFN is optimum it leads to synthesis and release of adequate 
amounts of PGE2 to induce the required degree of inflammation. This optimal action of IFN, PGE2 production and inflammatory reaction results in the initiation of inflammation resolution process such that homeostasis is restored. In the event the levels of IFN is inadequate as seen in severe COVID-19, the production of PGE2 will be suboptimal and so the inflammatory process is not adequate to initiate resolution of inflammation that results in persistence of inflammation as seen in severe COVID-19. This altered PGE2 production can result in inadequate LXA4 production and failure of wound healing. Furthermore, both PGE2 and LXA4 inhibit IFN and TNF- $\alpha$ production, whereas IFN and TNF- $\alpha$ are inducers of PGE2 production. Similar interaction between EPA/DHA and their eicosanoids is expected on IFN and TNF- $\alpha$. IFN (IFNgamma but not IFN- $\alpha$ and IFN- $\beta$ ) can enhance the production of TNF- $\alpha$ [257-259]. This positive and negative feedback among AA/EPA/DHA/GLA/DGLA/PGE2, LXA4, resolvins, protectins and maresins and IFN and TNF- $\alpha$ is needed to effectively eliminateSARS-CoV-2 and other microbes and eventually restore homeostasis. Thus, inadequate production of IFN- $\alpha$ in those with COVID-19 (that may in part be due to inadequate tissue content of GLA, DGLA, AA, EPA, DHA) leads to relatively low (but more than normal) levels of PGE2 [260] and excess of LXA4 (this ratio between PGE2 and LXA4 is relative). As a result of this relative deficiency of PGE2, excess production of TNF- $\alpha$ and IL-6 occurs leading to cytokine storm seen in severe COVID-19. Excess TNF- $\alpha$ causes decreased formation of AA/EPA/DHA due to its inhibitory action on desaturases [137]. This further aggravates deficiency of AA/EPA/DHA that can result in persistent excess production of $\mathrm{TNF}-\alpha$ and IL-6 due to the absence of negative feedback regulation of these fatty acids on cytokines. In this scenario, administration of GLA/DGLA/AA/EPA/DHA may be of significant benefit to suppress excess production of TNF- $\alpha$ and IL-6 and restore LXA4 levels to normal and halt this vicious circle of events. This implies that use of IFN alone will not be of benefit in COVID-19 unless and otherwise it is coadministered with BALs.

This imbalance in the immune response, cytokines and BALs is supported by the observation that in those with severe COVID-19 the germinal centers (where B and T cells are formed meet the demands of infections for adequate immune response) in the thoracic lymph nodes and spleens are absent that seems to be associated with high plasma levels of TNF- $\alpha$ implying that this cytokine is suppressing the immune system [261, 262]. These results are interesting in the light of the observation that 15-PGDH deficient animals not only have a 
twofold increase in bone marrow, colon, and liver PGE2 levels but also showed augmented hematopoietic capacity [185]. This implies that AA/EPA/DHA, IFN, TNF- $\alpha$ and PGE2 dysregulation results in inadequate immune response in COVID-19 (see Figure 10).

The recent report that bradykinin may have acritical role in cytokine storm seen in COVID-19 [263] can also be explained in terms of BALs. For instance, it is known that GLA, EPA and DHA (and possibly AA, PGE2, LXA4) can alter cell membrane fluidity and thus, alter the binding characteristics of bradykinin receptor $\left(\mathrm{B}_{2} \mathrm{R}\right)$ to bradykinin [264]. In addition, bradykinin stimulates PLA2 and enhances PGE2 formation [265-267]. PGE2 restrains mast cell activity and LXA4 can resolve inflammation induced by mast cell degranulation [268-270]. These results imply that the actions of bradykinin can be regulated and inhibited by LXA4 and other similar compounds resolvins, protectins and maresins (see Figure 11). Based on the concepts proposed here, we successfully treated 10 consecutive patients of COVID-19 by the administration of oral BALs, oral and inhalation of corticosteroids and heparin, oral B1, B6, B 12 and vitamin $\mathrm{C}$ (that form co-factors of EFA metabolism), and insulin (for hyperglycemia and incidentally it has anti-inflammatory action and enhances the activities of desaturases). In this open label study, 5 were asymptomatic, 3 had mild disease and 2 had moderately severe disease with co-morbid conditions type 2 diabetes mellitus, hypertension, and coronary heart disease. All have recovered completely without any side effects. In addition, these patients were on statins that are known to be of benefit in COVID-19 [271, 272].

\section{Future research strategies and therapeutic implications}

The concepts presented here can be verified by studying the effect of BALs (especially AA, EPA, DHA, LXA4, resolvins, protectin and maresins) on the survival and proliferation of SARS-CoV-2, SARS, and MERS in vitro and in vivo. It is predicted that BALs, especially LA and AA inactivate SARS-CoV-2, SARS, and MERS. Studies need to be performed to know whether PUFAs and their metabolites can influence the plasticity of macrophages to form M1 and M2 phenotypes. It is important to evaluate the role of desaturases, COX-2 and 5-, 12-, and 15-LOX enzymes and different types of phospholipases in COVID-19. It is predicted that those who have severe COVID-19 will show exaggerated expression of PLA2 and COX-2, whereas those who recover from COVID-19 are likely to show both COX-2 and 12-LOX and 15-LOX expression resulting in synthesis and release of adequate amounts of LXA4 to result in resolution of 
inflammation (see Figs. 5-8). This can be confirmed by measuring plasma levels of various BALs that will throw light whether a deficiency of LXA4, resolvins, protectins and maresins could be responsible for the severe COVID-19 and high degree mortality. It is predicted that timely production of PGE2 and LXA4 may fail to occur in these patients (see Figs. 5-8). Similarly, a close association between the plasma levels of IL-6, TNF- $\alpha$ and IFN and various BALs could be seen that could be correlated to the clinical picture.

Based on the evidence presented here, it is suggested that LA, GLA, DGLA, AA, EPA and DHA could be administered to prevent and manage COVID-19. Of all the BALs, it is likely that LA and AA may be of significant benefit in the treatment of COVID-19. The clinical implications of potential use of BALs in the prevention and treatment of COVID-19 lies in the fact that the antibodies developed against SARS-CoV-2 (either due to infection or immunization) may not last long enough to prevent a second infection. Alternatively, SARS-CoV-2 may undergo substantial mutation(s) such that the initial immunization against the current strain(s) may not work against the mutated viruses. In such a scenario, it is worthwhile to investigate whether a combination of vaccine against SARS-CoV-2 and BALs (especially LA and AA) will be of significant benefit in preventing COVID-19. Since BALs have the broad property of inactivating all types of enveloped viruses, it is likely that their (BALs, especially AA) administration may work in the prevention and treatment of all types of SARs viruses irrespective of changes in their genome.

Conflict of interest: Nil.

Source funding: Nil.

Acknowledgements: This work was financially supported by the Government of the Russian Federation through the ITMO Fellowship and Professorship Program to UND.

Dedication: This work is dedicated to my teacher Prof. E N B Sarma, guide, adviser, and philosopher. 


\section{Legends to figures and tables:}

\section{Legends to Figures and Tables:}

Figure 1A. Structure of SARS-CoV-2 that causes COVID-19. Note the structural similarity with Swine flu virus given in Figure 1B.

Figure 1B. Structure of the Swine flu A/Mexico/09 (H1N1) virus.

For comparison between influenza virus and the corona virus see Table 2 .

Figure 2. Scheme showing the actions of ACE and ACE2 and their role in the regulation of blood pressure, humoral balance, inflammation, cell proliferation, hypertrophy, and fibrosis.

The ACE/AngII/AT1R axis and the ACE2 / Ang 1-7 / MAS axis balance each other. Ang 1-7 is known to restore polyunsaturated fatty acids content of cells to normal especially in diabetes mellitus. Thus implies that there is a close interaction between Ang 1-7 and BALs and possibly some of the beneficial actions of Ang 1-7 on vascular tissue could be due to its actions on EFA metabolism (see Singh K, Singh T, Sharma PL. J Exp Pharmacol 2010: 2: 163-168. DOI: 10.2147/JEP.S14342).

Figure 3A. Scheme showing the metabolism of essential fatty acids, their role in inflammation and cytoprotection of endothelial cells.

Note that corticosteroids block the activity of PLA2, desaturases, COX-2 and LOX and thus, produce EFAs/PUFAs deficiency, inhibit the formation of PGE2 and LTs and of LXA4/resolvins, protectins and maresins. Statins enhance the activities of desaturases and increase the formation of GLA, DGLA, AA and of LXA4/resolvins/protectin/maresins. TNF- $\alpha$ and IL-6 decrease the activity of desaturases and thus, decrease the formation of GLA, DGLA and AA but enhance the activity of COX-2 and thus, produce EFA/PUFAs deficiency but increase the formation of PGE2. TNF- $\alpha$ and IL-6 stimulate PLA2 and thus, increase the release of AA form the cell membrane lipid pool. Thus, both corticosteroids and TNF- $\alpha$ and IL-6 produce EFA/PUFAs deficiency state but have opposite actions on PLA2, and PGE2 formation. 
Figure 3B. Scheme showing the relationship among SARS-CoV-2 and other enveloped viruses induced events on EFA metabolism, pro- and anti-inflammatory cytokines and their modulation by steroids and statins. For details see text. Modified from Das UN. J Inflammation Res 3: 143170.

Figure 4. A. Scheme showing potential interaction(s) among invading microbes including SARSCoV-2, host cell (target tissue/cell), immunocytes including macrophages and bioactive lipids including GLA/DGLA/AA/EPA/DHA, LXA4, PGE2, lipid peroxides (LP), activity of PLA2 COX-2 and LOX enzymes, CO, NO, H2S, and soluble epoxide hydrolase (sEH) and their relationship to the ability of microbes to infect the host cell and the response of host cell to infection. B. Similarly, potential interaction between tumor host cell (refers to surrounding normal cells present in the microenvironment of tumor) and the role of COX-2, LOX enzymes and the formation of PGE2/LXA4 and their effect(s) on tumor cell.

Legend to figure 4:

(A) When a microbe (including SARS-CoV-2) invades a normal cell (host cell), it may increase the production of PGE2 using its own (or host cell) COX-2. Microbe (using its LPS) or by activating host cell LOX enzymes leads to the formation of LXA4 that negates the synthesis or action of PGE2. Microbial infection activates immunocytes leading to release of IL-6, TNF-a that enhance the production of NO, CO, H2S and other ROS that can kill the microbes. Microbes can also activate PLA2 that induces the release of AA/EPA/DHA from the cell membrane lipid pool that are utilized for the formation of PGE2, LXA4 and lipid peroxides. Depending on the stage of the inflammation initially there will be activation of iPLA2 (inducible phospholipase A2) that induces the release of AA that is directed to form PGE2 and activation of M1 resulting in inflammation. Once PGE2 levels reach the peak it triggers the activation of soluble PLA2 (sPLA2) and cytosolic PLA2 (cPLA2) inducing the release of second wave of AA and simultaneously activation of LOX leading to the formation of LXA4 and M2. This results in suppression of inflammation and restoration of homeostasis. BALS especially AA/EPA/DHA/LXA4 and lipid peroxides kill the microbes including SARS-CoA2. Lipid peroxides, LXA4 and AA/EPA/DHA may inhibit the activity of soluble epoxide hydrolase that leads to suppression of inflammation. Mesenchymal stem cells (MSCs) produce LXA4 to bring about their beneficial actions. 
(B) Similar set of events occur in the presence of tumor cell. There is a crosstalk between normal cells surrounding the tumor cell and immunocytes. Tumor cells have high COX2 activity that may lead to increased formation of PGE2 (COX-2 of tumor cells may act on normal cells or on exposure to tumor cells normal cells may enhance their COX-2 activity). On exposure to tumor cell, PLA2 of normal cells/immunocytes is activated to induce the release of $\mathrm{AA} / \mathrm{EPA} / \mathrm{DHA}$ to produce $\mathrm{PGE} 2$ or LXA4. If the released AA/EPA/DHA are converted to form excess of lipid peroxides and/or LXA4, then tumor cell growth is inhibited or undergoes apoptosis. If he activity of COX-2 dominates then AA is converted to PGE2 that induce immunosuppression and enhances tumor cell growth. IL-6 and TNF-a released by immunocytes induce the release of ROS that can enhance the formation of lipid peroxides to induce apoptosis of tumor cells. But both IL6 and TNF-a can induce deficiency of AA/EPA/DHA in the tumor cells and surrounding normal cells and immunocytes by inhibiting the activities of desaturases.

See text for further details.

Figure 5. Scheme showing M1 and M2 macrophages and various cytokines produced by them and their respective functions.

DGLA, AA, EPA and DHA have anti-inflammatory actions and inhibit the production of proinflammatory TNF- $\alpha$, IL-2 and IL-1 and facilitate the generation of M2 macrophages.

PGE 1 formed from DGLA, LXA4 from LXA4 are anti-inflammatory in nature.

Resolvins $(\mathrm{R})$, protectins $(\mathrm{P})$, and maresins $(\mathrm{M})$ formed from EPA and DHA are antiinflammatory and block the production of TNF, IL-1, IL-2.

PGE2, Leukotrienes B4, D4 and E4 formed from AA are pro-inflammatory in nature.

LXA4, resolvins, protectins and maresins inhibit the production of PGE2 and LTs.

Leukotrienes (of 5 series) are also formed from EPA that have pro-inflammatory action but are much less potent compared to LTs formed from AA.

EPA and DHA inhibit the production of PGE2.

Figure 6A. Scheme showing potential relationship among AA, PGE2, LXA4 and viral load in a COVID-19 patient who recovers. AA is released from the cell membrane in two phases, first 
phase is used for PGE2 synthesis, whereas the second phase is meant for LXA4 synthesis. Once PGE2 concentration reaches its peak, LXA4 synthesis is triggered that induces resolution of inflammation. AA release is triggered by SARS-CoV-2 and other infections.

Figure 6B. Scheme showing potential relationship among AA, PGE2, LXA4 and viral load in a COVID-19 patient who succumbs to the disease. Absence of biphasic nature of AA release and failure of PGE2 to reach its peak to trigger LXA4 synthesis that results in failure of resolution of inflammation fails (compare with Fig 7A). DGLA, EPA and DHA (not shown in the figure) may have actions/functions like AA. Desaturases activities fall with age.

Figure 7. Scheme showing the metabolism of AA and how pro-inflammatory LTA4 can be converted to anti-inflammatory LXA4 by the action of PGE2. Similar conversion of proinflammatory PGs, TXs and LTs to anti-inflammatory resolvins, protectins and maresins may occur.

Figure 8. Scheme of events that are likely to occur in SARS-CoV-2 infection and the two phases of cytokine response in COVID-19. Initially there will be hyperinflammation due to release of excess of pro-inflammatory cytokines. Subsequently there could occur diminished release of cytokines and immunosuppression. During the hyperinflammation phase dexamethasone and anti-TNF or anti-IL-6 and other cytokine antagonists will be helpful. Once immunosuppression sets in dexamethasone is not of significant help and inflammation resolution molecules are needed to enhance recovery process. In severe COVID-19 there will be persistently elevated PGE2 and LXA4 fails to rise to induce resolution of inflammation. In contrast, in mild COID-19, initially there will be an elevation in PGE2 that falls to the normal physiological level that is accompanied by increase in LXA4 to induce resolution of inflammation as shown in the figure. Compare this with figure 9. This figure is modified from Das UN. Arch Med Sci 2014; 10: 325-335.

Figure 9. Viral and host factors influence IFN response. When the viral burden is low, IFN production will be adequate to clear the viral infection effectively that is probably accompanied by initial PGE2 response and timely LXA4 generation to resolve inflammation. When viral load is high, virus itself may suppress IFN production and stimulate strong PGE2 and weak LXA4 responses leading to severe COVID-19. Late onset IFN response may aggravate inflammation as seen in severe COVID-19. PGE2 response may parallel IFN response. AA release will occur in both mild and severe SARS-CoV-2 infection, but the product formed, and their concentrations (PGE2 and LXA4) may differ as shown in the figure. Compare this with figures 5 and 6. 
Figure 10. Scheme showing interaction among SARS-CoV-2, host cells, immunocytes, AA and cytokines. Similar interaction may exist among SARS-CoV-2, host cells/immunocytes, EPA/DHA and resolvins, protectins and maresins.

Figure 11. Scheme showing potential involvement of bradykinin in severe COVID-19 as proposed by Garvin et al (263) and how it could be modulated by BALs.

Table 1. Comparison between Influenza virus and coronavirus (see Figures 1A and 1B also). Table 2. Clinical features of COVID-19. 


\section{References:}

1. Yan R, Zhang Y, Li Y, Xia L, Guo Y, Zhou Q (2020) Structural basis for the recognition of the SARS-CoV-2 by full-length human ACE2. Science 10.1126/science.abb2762 (2020).

2. Ou X, Liu Y, Lei X, Li P, Mi D, Ren L, et al. (2020) Characterization of spike glycoprotein of SARS-CoV-2 on virus entry and its immune cross-reactivity with SARS-CoV. Nat Communications (2020) 11:1620 | https://doi.org/10.1038/s41467-020-15562-9.

3. Yuan M, Wu NC, Zhu X, Lee C-C D, So RTY, Lv H, et al. (2020) A highly conserved cryptic epitope in the receptor-binding domains of SARS-CoV-2 and SARS-CoV. Science 10.1126/science.abb7269 (2020).

4. Zheng Z, Monteil VM, Maurer-Stroh S, et al. Monoclonal antibodies for the S2 subunit of spike of SARS-CoV-1 cross-react with the newly-emerged SARS-CoV-2. Euro Surveill 2020;25(28):2000291. doi:10.2807/1560-7917.ES.2020.25.28.2000291.

5. Corrêa Giron C, Laaksonen A, Barroso da Silva FL. On the interactions of the receptorbinding domain of SARS-CoV-1 and SARS-CoV-2 spike proteins with monoclonal antibodies and the receptor ACE2. Virus Res 2020;285:198021. doi:10.1016/j.virusres.2020.198021.

6. Khan S, Nakajima R, Jain A, et al. Analysis of Serologic Cross-Reactivity Between Common Human Coronaviruses and SARS-CoV-2 Using Coronavirus Antigen Microarray. Preprint. bioRxiv. 2020;2020.03.24.006544. Published 2020 Mar 25. doi: $10.1101 / 2020.03 .24 .006544$.

7. Xu X, Chen P, Wang J, Feng J, Zhou H, Li X, Zhong W, Hao P (2020) Evolution of the novel coronavirus from the ongoing Wuhan outbreak and modeling of its Spike protein for risk of human transmission. Sci China Life Sci 63: 457-460.

8. Asadi-Pooya AA, Simani L (2020) Central nervous system manifestations of COVID-19: A systematic review. J Neurol Sci 413: 116832. doi:10.1016/j.jns.2020.116832. 
9. Ellul MA, Benjamin L, Singh B, et al. (2020) Neurological associations of COVID19. Lancet Neurol 19(9): 767-783. doi:10.1016/S1474-4422(20)30221-0.

10. Hanafi R, Roger PA, Perin B, et al. (2020) COVID-19 Neurologic Complication with CNS Vasculitis-Like Pattern. AJNR Am J Neuroradiol 41: 1384-1387. doi:10.3174/ajnr.A6651.

11. Huang L, Zhao P, Tang D, et al. (2020) Cardiac Involvement in Patients Recovered From COVID-2019 Identified Using Magnetic Resonance Imaging. JACC Cardiovasc Imaging. S1936-878X(20)30403-4. doi:10.1016/j.jcmg.2020.05.004.

12. Kohli U, Lodha R (2020) Cardiac Involvement in Children With COVID-19. Indian Pediatr S097475591600222.

13. Eapen MS, Lu W, Gaikwad AV, et al. (2020) Endothelial to mesenchymal transition (EndMT): a precursor to post-SARS-CoV-2 infection (COVID-19) interstitial pulmonary fibrosis and vascular obliteration? Eur Respir J 2003167. doi:10.1183/13993003.031672020.

14. Teng F, Liu X, Guo SB, et al. (2019) Community-acquired bacterial co-infection predicts severity and mortality in influenza-associated pneumonia admitted patients. $\mathrm{J}$ Infect Chemother 25(2):129-136. doi:10.1016/j.jiac.2018.10.014.

15. MacIntyre CR, Chughtai AA, Barnes M, et al. (2018) The role of pneumonia and secondary bacterial infection in fatal and serious outcomes of pandemic influenza a(H1N1)pdmo9. BMC Infect Dis 18(1):637. doi:10.1186/s12879-018-3548-0.

16. Short KR, Kedzierska K, van de Sandt CE. (2018) Back to the Future: Lessons Learned From the 1918 Influenza Pandemic. Front Cell Infect Microbiol 8:343. doi:10.3389/fcimb.2018.00343.

17. Muñoz P, Galar A, Catalán P, et al. (2020) The first 100 cases of COVID-19 in a Hospital in Madrid with a 2-month follow-up. Rev Esp Quimioter 2020; munoz30jul2020. doi: $10.37201 / \mathrm{req} / 072.2020$. 
18. Wu J, Mamas M, Rashid M, et al. (2020) Patient response, treatments and mortality for acute myocardial infarction during the COVID-19 pandemic. Eur Heart J Qual Care Clin Outcomes 2020;qcaa062. doi:10.1093/ehjqcco/qcaa062.

19. Li F, Li W, Farzan M, Harrison SC (2005) Structure of SARS coronavirus Spike receptorbinding domain complexed with receptor. Science 309:1864-1868.

20. Wan Y, Shang J, Graham R, Baric RS, Li F (2020) Receptor recognition by novel coronavirus from Wuhan: an analysis based on decade-long structural studies of SARS. J Virol 94: e00127-20.

21. Zhang H, Penninger JM, Li Y, Zhong N, Slutsky AS (2020) Angiotensin-converting enzyme 2 (ACE2) as a SARS-CoV-2 receptor: molecular mechanisms and potential therapeutic target. Intensive Care Med 46: 586-590.

22. Wu KL, Peng GQ, Wilken M, Geraghty RJ, Li F (2012) Mechanisms of host receptor adaptation by severe acute respiratory syndrome coronavirus. J Biol Chem 287:89048911.

23. Imai, Y., Kuba, K., Rao, S. et al (2005) Angiotensin-converting enzyme 2 protects from severe acute lung failure. Nature 436: 112-116.

24. Corrêa Giron C, Laaksonen A, Barroso da Silva FL (2020) On the interactions of the receptor-binding domain of SARS-CoV-1 and SARS-CoV-2 spike proteins with monoclonal antibodies and the receptor ACE2. Virus Res 285: 198021. doi:10.1016/j.virusres.2020.198021.

25. Yuan M, Wu NC, Zhu X, et al. (2020) A highly conserved cryptic epitope in the receptor binding domains of SARS-CoV-2 and SARS-CoV. Science 368(6491): 630-633. doi: $10.1126 /$ science.abb7269.

26. Lan J, Ge J, Yu J, et al. (2020) Structure of the SARS-CoV-2 spike receptor-binding domain bound to the ACE2 receptor. Nature 581(7807): 215-220. doi:10.1038/s41586020-2 180-5.

27. Zou, X, Chen K, Zou J, Han P, Hao J. Han Z, et al (2020) The single-cell RNA-seq data analysis on the receptor $\mathrm{ACE} 2$ expression reveals the potential risk of different human organs vulnerable to Wuhan 2019-nCoV infection. Front Med 14: 185-192. 
28. Moreira RDS (2020) COVID-19: intensive care units, mechanical ventilators, and latent mortality profiles associated with case-fatality in Brazil. Cad Saude Publica 36(5): e00080020. doi:10.1590/0102-311x00080020.

29. Zhou F, Yu T, Du R, et al. (2020) Clinical course and risk factors for mortality of adult inpatients with COVID-19 in Wuhan, China: a retrospective cohort study Lancet 395(10229): 1054-1062. doi:10.1016/So 140-6736(20)30566-3.

30. Duca A, Memaj I, Zanardi F, et al. Severity of respiratory failure and outcome of patients needing a ventilatory support in the Emergency Department during Italian novel coronavirus SARS-CoV2 outbreak: Preliminary data on the role of Helmet CPAP and Non-Invasive Positive Pressure Ventilation. E Clinical Medicine 24: 100419. doi:10.1016/j.eclinm.2020.100419.

31. Zhang H, Kang Z, Gong H, Xu D, Wang J, Li Z, Cui X, Xiao J, Meng T, Zhou W, Liu $\mathrm{J}$, Xuet H (2020) The digestive system is a potential route of 2019-nCov infection: a bioinformatics analysis based on single-cell transcriptomes. Preprint at https:// www.biorxiv.org/content/10.1101/2020.01.30.927806v1 (2020).

32. Xu H, Zhong L. Deng J, Peng J, Dan H, Zeng X, Li T, Chen Q (2020) High expression of ACE2 receptor of 2019-nCoV on the epithelial cells of oral mucosa. Int J Oral Sci 12: 8.

33. Kaye R, Chang CWD, Kazahaya K, Brereton J, Denneny JC $3^{\text {rd }}$ (2020) COVID-19 Anosmia Reporting Tool: Initial Findings [published online ahead of print, 2020 Apr 28]. Otolaryngol Head Neck Surg 2020;194599820922992. doi:10.1177/0194599820922992.

34. Núñez-Delgado A (2020) What do we know about the SARS-CoV-2 coronavirus in the environment?. Sci Total Environ 727: 138647. doi:10.1016/j.scitotenv.2020.138647.

35. Aboubakr HA, Sharafeldin TA, Goyal SM (2020) Stability of SARS-CoV-2 and other coronaviruses in the environment and on common touch surfaces and the influence of climatic conditions: A review. Transbound Emerg Dis 10.1111/tbed.13707. doi:10.1111/tbed.13707. 
36. Ali M, Zaid M, Saqib MAN, Ahmed H, Afzal MS (2020) SARS-CoV-2 and the hidden carriers: Sewage, feline, and blood transfusion. J Med Virol 10.1002/jmv.25956. doi:10.1002/jmv.25956.

37. Jones DL, Baluja MQ, Graham DW, et al. Shedding of SARS-CoV-2 in feces and urine and its potential role in person-to-person transmission and the environment-based spread of COVID-19. Sci Total Environ 749: 141364. doi:10.1016/j.scitotenv.2020.141364.

38. Fernandez-Nieto D, Ortega-Quijano D, Jimenez-Cauhe J, Burgos-Blasco P, Suarez-Valle A, Cortes-Cuevas JL, et al. (2020) Clinical and histological characterization of vesicular COVID-19 rashes: A prospective study in a tertiary care hospital. Clin Exp Dermatol https://doi.org/10.1111/ced.14277.

39. Bernstein KE, Giani JF, Shen XZ, Gonzalez-Villalobos RA (2014) Renal angiotensinconverting enzyme and blood pressure control. Curr Opin Nephrol Hypertens 23:106112.

40. Conti P, Caraffa A, Tetè G, et al. (2020) Mast cells activated by SARS-CoV-2 release histamine which increases IL-1 levels causing cytokine storm and inflammatory reaction in COVID-19. J Biol Regul Homeost Agents 34(5): 10.23812/20-2EDIT. doi:10.23812/20-2EDIT.

41. Ortega JT, Serrano ML, Jastrzebska B (2020) Class A G Protein-Coupled Receptor Antagonist Famotidine as a Therapeutic Alternative Against SARS-CoV2: An In Silico Analysis. Biomolecules 10(6): 954. doi:10.3390/biom 10060954.

42. Freedberg DE, Conigliaro J, Wang TC, et al. (2020) Famotidine Use Is Associated With Improved Clinical Outcomes in Hospitalized COVID-19 Patients: A Propensity Score Matched Retrospective Cohort Study. Gastroenterology 159(3): 1129-1131.e3. doi:10.1053/j.gastro.2020.05.053.

43. Hogan Ii RB, Hogan Iii RB, Cannon T, et al. (2020) Dual-histamine receptor blockade with cetirizine - famotidine reduces pulmonary symptoms in COVID-19 patients Pulm Pharmacol Ther 63: 101942. doi:10.1016/j.pupt.2020.101942. 
44. Mather JF, Seip RL, McKay RG. (2020) Impact of Famotidine Use on Clinical Outcomes of Hospitalized Patients With COVID-19. Am J Gastroenterol 10. 14309/ajg.0000000000000832. doi:10.14309/ajg.0000000000000832.

45. Erdos EG, Skidgel RA (1985) Structure and functions of human angiotensin I converting enzyme (kininase II). Biochem Soc Trans 13: 42-44.

46. Casarini DE, Boim MA, Stella RC, Krieger-Azzolini MH, Krieger JE, Schor N (1997) Angiotensin I converting enzyme activity in tubular fluid along the rat nephron. Am J Phys 272: F405-F409.

47. Erdos EG, Skidgel RA (1985) Structure and functions of human angiotensin I converting enzyme (kininase II). Biochem Soc Trans 13: 42-44.

48. Casarini DE, Boim MA, Stella RC, Krieger-Azzolini MH, Krieger JE, Schor N (1997) Angiotensin I converting enzyme activity in tubular fluid along the rat nephron. Am J Phys 272: F405-F409.

49. Gonzalez-Villalobos RA, Billet S, Kim C, Satou R, Fuchs S, Bernstein KE, et al (2011) Intrarenal angiotensin-converting enzyme induces hypertension in response to angiotensin I infusion. J Am Soc Nephrol 22: 449-459.

50. Giani JF, Eriguchi M, Bernstein EA, Katsumata M, Shen XZ, Li L, et al (2017) Renal tubular angiotensin converting enzyme is responsible for nitro-L-arginine methyl ester (L-NAME)- induced salt sensitivity. Kidney Int 91: 856-867.

51. Padda, RS., Shi, Y., Lo, CS., Zhang, SL., Chan, JS (2015) Angiotensin-(1-7): a novel peptide to treat hypertension and nephropathy in diabetes? J Diabetes Metab 6: 10. DOI: 10.4172/2155-6156.1000615p. 6doi: https://doi.org/ 10.4172/2155-6156.1000615

52. Shi Y, Lo CS, Padda R, Abdo S, Chenier I, Filep JG, et al (2015) Angiotensin-(1-7) prevents systemic hypertension, attenuates oxidative stress and tubulointerstitial fibrosis, and normalizes renal angiotensin-converting enzyme 2 and Mas receptor expression in diabetic mice. Clin Sci (Lond) 128: 649-663.

53. Donoghue M, Hsieh F, Baronas E, Godbout K, Gosselin M, Stagliano N, et al (2000) A novel angiotensin-converting enzyme-related carboxypeptidase (ACE2) converts angiotensin I to angiotensin 1-9. Circ Res 87: E1-E9.

54. Kuba K, Imai Y, Rao S, Gao H, Guo F, Guan B, et al (2005) A crucial role of angiotensin converting enzyme 2 (ACE2) in SARS coronavirus-induced lung injury. Nat Med 11: $875-879$. 
55. Osterreicher CH, Taura K, De Minicis S, Seki E, Penz-Osterreicher M, Kodama Y, et al (2009) Angiotensin-converting-enzyme 2 inhibits liver fibrosis in mice. Hepatology 50: 929-938.

56. Lely AT, Hamming I, van Goor H, Navis GJ (2004) Renal ACE2 expression in human kidney disease. J Pathol 204: 587-593.

57. Liu CX, Hu Q, Wang Y, Zhang W, Ma ZY, Feng JB, et al (2011) Angiotensin-converting enzyme (ACE) 2 overexpression ameliorates glomerular injury in a rat model of diabetic nephropathy: a comparison with ACE inhibition. Mol Med 17: 59-69.

58. Li Y, Xiao S-Y (2020) Hepatic Involvement in COVID-19 Patients: Pathology, Pathogenesis, and Clinical Implications. J Med Virology. https://doi.org/10.1002/jmv.25973.

59. Batlle D, Soler MJ, Sparks MA, et al. (2020) Acute Kidney Injury in COVID-19: Emerging Evidence of a Distinct Pathophysiology. J Am Soc Nephrol 31(7): 1380-1383. doi:10.1681/ASN.2020040419.

60. Hirsch JS, Ng JH, Ross DW, et al. (2020) Acute kidney injury in patients hospitalized with COVID-19. Kidney Int 98(1): 209-218. doi:10.1016/j.kint.2020.05.006.

61. Li Y, Xiao S-Y (2020) Hepatic Involvement in COVID-19 Patients: Pathology, Pathogenesis, and Clinical Implications. J Med Virology. https://doi.org/10.1002/jmv.25973.

62. Ackermann M, Verleden SE, Kuehnel M, Haverich A, Welte T, Laenger T, et al (2020) Pulmonary Vascular Endothelialitis, Thrombosis, and Angiogenesis in Covid-19. New Engl J Med DOI: 10.1056/NEJMoa2015432.

63. Abrams JY, Godfred-Cato SE, Oster ME, et al. (2020) Multisystem Inflammatory Syndrome in Children (MIS-C) Associated with SARS-CoV-2: A Systematic Review [published online ahead of print, 2020 Aug 5]. J Pediatr So022-3476(20)30985-9. doi:10.1016/j.jpeds.2020.08.003.

64. Nakra NA, Blumberg DA, Herrera-Guerra A, Lakshminrusimha S. (2020) Multi-System Inflammatory Syndrome in Children (MIS-C) Following SARS-CoV-2 Infection: Review 
of Clinical Presentation, Hypothetical Pathogenesis, and Proposed Management. Children (Basel) 7(7):69. doi:10.3390/children7070069.

65. Feldstein LR, Rose EB, Horwitz SM, et al. (2020) Multisystem Inflammatory Syndrome in U.S. Children and Adolescents. N Engl J Med 383(4): 334-346. doi:10.1056/NEJMoa2021680.

66. Dufort EM, Koumans EH, Chow EJ, et al. (2020) Multisystem Inflammatory Syndrome in Children in New York State. N Engl J Med 383(4): 347-358. doi:10.1056/NEJMoa202 1756.

67. Speert DP, Wannamaker LW, Gray ED, Clawson CC (1979) Bactericidal effect of oleic acid on group A streptococci: mechanism of action. Infect Immun 26: 1202-1210.

68. Heczko PB, Lutticken R, Hryniewicz W, Neugebauer M, Pulverer G (1979) Susceptibility of Staphylococcus aureus and Group A, B, C, and G streptococci to free fatty acids. J Clin Microbiol 9: 333-335.

69. Wyss O, Ludwig BJ, Joiner RR (1945) The fungistatic and fungicidal action of fatty acids and related compounds. Arch Biochem 7: 415-424.

70. Kohn A, Gitelman J, Inbar M (1980) Unsaturated free fatty acids inactivate animal enveloped viruses. Arch Virol 66: 301-306.

71. Das UN (1985) Anti-biotic-like action of essential fatty acids. Can Med Assoc J 132: 1350.

72. Das UN (1985) Can essential fatty acid deficiency predispose to AIDS? Can Med Assoc J 132: 900-902.

73. Das UN (2018) Arachidonic acid and other unsaturated fatty acids and some of their metabolites function as endogenous antimicrobial molecules: A review. J Adv Res 11: 5766.

74. Stock CC, Francis Jr T (1940) The inactivation of the virus of epidemic influenza by soaps. J Exp Med $71: 661-681$.

75. Sands J, Auperin D, Snipes W (1979) Extreme sensitivity of enveloped viruses, including herpes simplex, to long chain unsaturated monoglycerides and alcohols. Antimicrob Agents Chemother $15: 67-73$. 
76. Skerrett SJ, Henderson WR, Martin TR. (1990) Alveolar macrophage function in rats with severe protein calorie malnutrition. Arachidonic acid metabolism, cytokine release, and antimicrobial activity. J Immunol 144(3): 1052-1061.

77. Brown GP, Monick MM, Hunninghake GW. (1988) Human alveolar macrophage arachidonic acid metabolism. Am J Physiol 254(6 Pt 1$)$ : C809-C815. doi:10.1152/ajpcell.1988.254.6.C809.

78. Castro M, Morgenthaler TI, Hoffman OA, Standing JE, Rohrbach MS, Limper AH (1993) Pneumocystis carinii induces the release of arachidonic acid and its metabolites from alveolar macrophages. Am J Respir Cell Mol Biol 9(1): 73-81. doi:10.1 165/ajrcmb/9.1.73.

79. Chauncey JB, Peters-Golden M, Simon RH (1988) Arachidonic acid metabolism by rat alveolar epithelial cells. Lab Invest 58(2): 133-140.

80. Castro M, Ralston NV, Morgenthaler TI, Rohrbach MS, Limper AH (1994) Candida albicans stimulates arachidonic acid liberation from alveolar macrophages through alphamannan and beta-glucan cell wall components. Infect Immun 62(8): 3138-3145. doi:10.1128/IAI.62.8.3138-3145.1994.

81. Jayaraja S, Dakhama A, Yun B, et al. (2016) Cytosolic phospholipase A2 contributes to innate immune defense against Candida albicans lung infection. BMC Immunol 17(1): 27. Published 2016 Aug 8. doi:10.1186/s 12865-016-0165-9.

82. Cifone MG, Botti D, Festuccia C, et al. (1993) Involvement of phospholipase A2 activation and arachidonic acid metabolism in the cytotoxic functions of rat NK cells. Cell Immunol 148(2): 247-258. doi:10.1006/cimm.1993.1109.

83. Bray RA, Brahmi Z. (1986) Role of lipoxygenation in human natural killer cell activation. J Immunol 136(5): 1783-1790.

84. Grazia Cifone M, Roncaioli P, Cironi L, et al. (1997) NKR-P1A stimulation of arachidonate-generating enzymes in rat NK cells is associated with granule release and cytotoxic activity. J Immunol 159(1): 309-317. 
85. Goicoa MA, Mariani AL, Palacios MF, et al. (1992) Defect of NK regulation in HIVinfected patients. Arch AIDS Res 6(1-2): 15-26.

86. Abraham RT, McKinney MM, Forray C, Shipley GD, Handwerger BS (1986) Stimulation of arachidonic acid release and eicosanoid biosynthesis in an interleukin 2-dependent $\mathrm{T}$ cell line. J Immunopharmacol 8(2):165-204. doi:10.3109/08923978609028614.

87. Bomalaski JS, Steiner MR, Simon PL, Clark MA (1992) IL-1 increases phospholipase A2 activity, expression of phospholipase A2-activating protein, and release of linoleic acid from the murine T helper cell line EL-4. J Immunol 148(1): 155-160.

88. Nokta MA, Hassan MI, Loesch KA, Pollard RB (1995) HIV-induced TNF-alpha regulates arachidonic acid and PGE2 release from HIV-infected mononuclear phagocytes. Virology 208(2): 590-600. doi:10.1006/viro.1995.1190.

89. Sanderson P, Thies F, Calder PC (2000) Extracellular release of free fatty acids by rat T lymphocytes is stimulus-dependent and is affected by dietary lipid manipulation. Cell Biochem Funct 18(1): 47-58. doi:10.1002/(SICI)1099-0844(200001/03)18:1<47::AID$\mathrm{CBF} 848>3.0 . \mathrm{CO} ; 2-8$.

90. Goldyne ME, Stobo JD (1982) Human monocytes synthesize eicosanoids from T lymphocyte-derived arachidonic acid. Prostaglandins 24(5): 623-630. doi:10.1016/00906980(82)90032-6.

91. Schulam PG, Shearer WT (1990) Evidence for 5-lipoxygenase activity in human B cell lines. A possible role for arachidonic acid metabolites during B cell signal transduction. J Immunol 144(7): 2696-2701.

92. Nokta MA, Hassan MI, Loesch K, Pollard RB (1996) Human cytomegalovirus-induced immunosuppression. Relationship to tumor necrosis factor-dependent release of arachidonic acid and prostaglandin E2 in human monocytes. J Clin Invest 97(11): 26352641. doi:10.1172/JCI 118713. 
93. Gimenez AP, Wu YZ, Paya M, Delclaux C, Touqui L. Goossens PL (2004) High bactericidal efficiency of type iia phospholipase A2 against Bacillus anthracis and inhibition of its secretion by the lethal toxin. J Immunol 173: 521-530.

94. Raymond B, Leduc D, Ravaux L, Le Goffic R, Candela T, Raymondjean M, et al (2007) Edema toxin impairs anthracidal phospholipase A2 expression by alveolar macrophages. PLoS Pathog 3: e187.

95. Raymond B, Ravaux L, Mémet S, Wu Y, Sturny-Leclère A, Leduc D, et al (2010) Anthrax lethal toxin down-regulates type-IIA secreted phospholipase $\mathrm{A}(2)$ expression through MAPK/NF-kappaB inactivation. Biochem Pharmacol 79: 1149-1155.

96. Gimenez AP, Wu Y-Z, Paya M, Delclau C, Touqui L, Goossens PL (2004) High bactericidal efficiency of type IIA phospholipase A2 against Bacillus anthracis and inhibition of its secretion by the lethal toxin. J Immunol 173: 521-530.

97. Territo MC, Golde DW (1979) The function of human alveolar macrophages. Res J Reticuloendothel Soc 25: 111-120.

98. Baughn RE, Bonventre PF (1975) Phagocytosis and intracellular killing of Staphlococcus aureus by normal mouse peritoneal macrophages. Infect Immun 12: 346-352.

99. LaForce FM, Kelly WJ, Huber GL (1973) Inactivation of staphylococci by alveolar macrophages with preliminary observations on the importance of alveolar lining material. Am Rev Respir Dis 108: 784-790.

100. Juers JA, Rogers RM, McCurdy JB, Cook WW (1976) Enhancement of bactericidal capacity of alveolar macrophages by human alveolar lining material. J Clin Invest 58: 271-275.

101. Dubos RJ (1947) The effect of lipids and serum albumin on bacterial growth. J Exp Med 85: 9-22.

102. Nieman C (1954) Influence of trace amounts of fatty acids on the growth of microorganisms. Bacteriol Rev 18: 147-162.

103. Kabara JJ, Swieczkowski DM, Conley AJ, Truant JP (1972) Fatty acids and derivatives as antimicrobial agents. Antimicrob Agents Chemother 2: 23-28.

104. Larsson K, Noren B, Odham G (1975) Antimicrobial effect of simple lipids with different branches at the methyl end group. Antimicrob Agents Chemother 8: 742-750. 
105. Heczko PB, Lutticken R, Hryniewicz W, Neugebauer M, Pulverer G (1979) Susceptibility of Staphylococcus aureus and Group A, B, C, and G streptococci to free fatty acids. J Clin Microbiol 9: 333-335.

106. Wyss O, Ludwig BJ, Joiner RR (1945) The fungistatic and fungicidal action of fatty acids and related compounds. Arch Biochem 7: 415-424.

107. Schlager SI, Madden LD, Meltzer MS, Bara S, Mamula MJ (1983) Role of macrophage lipids in regulating tumoricidal activity. Cell Immunol 77: 52-68.

108. Cerquetti MC, Hovsepian E, Sarnacki SH, Goren NB (2008) Salmonella enterica serovar enteritidis dam mutant induces low NOS-2 and COX-2 expression in macrophages via attenuation of MAPK and NF-kappaB pathways. Microbes Infect 10: 1431-1439.

109. Raisch J, Rolhion N, Dubois A, Darfeuille-Michaud A, Bringer M-A (2015) Intracellular colon cancer-associated Escherichia coli promote protumoral activities of human macrophages by inducing sustained COX-2 expression. Lab Invest 95: 296-307.

110. Pandey RK, Dahiya Y, Sodhi A (2012) Mycobacterium indicus pranii downregulates MMP-9 and iNOS through COX-2 dependent and TNF- $\alpha$ independent pathway in mouse peritoneal macrophages in vitro. Microbes Infect 14: 348-356.

111. Hooks JJ, Chin SM, Srinivasan K, Momma Y, Hooper LC, Nagineni NC, Chan CC, Detrick B (2006) Human cytomegalovirus induced cyclooxygenase-2 in human retinal pigment epithelial cells augments viral replication through a prostaglandin pathway. Microbes Infect 8: 2236-2244.

112. Lim S-M, Jang HM, Jang S-E, Han MJ, Kim D-H (2017) Lactobacillus fermentum IM12 attenuates inflammation in mice by inhibiting NF-кB-STAT3 signalling pathway. Benef Microbes 8: 407-419.

113. Liu Y-W, Ong W-K, Su Y-W, Hsu C-C, Cheng T-H, Tsai Y-C (2016) Antiinflammatory effects of Lactobacillus brevis K65 on RAW 264.7 cells and in mice with dextran sulphate sodium-induced ulcerative colitis. Benef Microbes 7: 387-396.

114. Costa-Junior HM, Hamaty FC, da Silva Farias R, et al (2006) Apoptosis inducing factor of a cytotoxic T cell line: involvement of a secretory phospholipase A2. Cell Tissue Res 324: 255-266.

115. Milella M, Gismondi A, Roncaioli P, et al (1999) Beta 1 integrin crosslinking inhibits CD16-induced phospholipase D and secretory phospholipase A2 activity and 
granule exocytosis in human NK cells: role of phospholipase D in CD16-triggered degranulation. J Immunol 162: 2064-2072.

116. Parmentier JH, Muthalif MM, Nishimoto AT, et al (2001) 20Hydroxyeicosatetraenoic acid mediates angiotensin ii-induced phospholipase D activation in vascular smooth muscle cells. Hypertension 37: 623-629.

117. Das UN (2019) Can bioactive lipid(s) augment anti-cancer action of immunotherapy and prevent cytokine storm? Arch Med Res 50: 342-349.

118. Baranov V, Nagaeva O, Hammarstrom S, et al (2000) Lipids are a constitutive component of cytolytic granules. Histochem Cell Biol 14: 167-171.

119. Schlager SI, Meltzer MS, Madden LD (1983) Role of membrane lipids in the immunological killing of tumor cells, II. Effector cell lipids. Lipids 18: 483-488.

120. Schlager SI, Ohanian SH (1983) Role of membrane lipids in the immunological killing of tumor cells, I. Target cell lipids. Lipids 18: 475-482.

121. Schlager SI, Meltzer MS (1983) Role of macrophage lipids in regulating tumoricidal activity. II. Internal genetic and external physiologic regulatory factors controlling macrophage tumor cytotoxicity also control characteristic lipid changes associated with tumoricidal cells. Cell Immunol 80: 10-19.

122. Stolp B, Thelen F, Ficht X, et al (2020) Salivary gland macrophages and tissueresident $\mathrm{CD} 8+\mathrm{T}$ cells cooperate for homeostatic organ surveillance. Sci Immunol 5, eaaz4371. DOI: 10.1126/sciimmunol.aaz4371.

123. Frizzell H, Fonseca R, Christo SN, et al (2020) Organ-specific isoform selection of fatty acid-binding proteins in tissue-resident lymphocytes. Science Immunology eaay9283, DOI:10.1126/sciimmunol.aay9283.

124. Bouchery T, Harris NL (2017) Specific repair by discerning macrophages. Science 356: 1014 .

125. Salina AC, Souza TP, Serezani CH, Medeiros AI (2017) Efferocytosis-induced prostaglandin E2 production impairs alveolar macrophage effector functions during Streptococcus pneumoniae infection. Innate Immun 23: 219-227.

126. Norris PC, Arnardottir H, Sanger JM, Fichtner D, Keyes GS, Serhan CN (2016) Resolvin D3 multi-level proresolving actions are host protective during infection. Prostaglandins Leukot Essent Fatty Acids 22. pii: So952-3278(15)30052. 
127. Ramon S, Dalli J, Sanger JM, Winkler JW, Aursnes M, Tungen JE, et al (2016) The protectin PCTR 1 is produced by human M2 macrophages and enhances resolution of infectious inflammation. Am J Pathol 186: 962-973.

128. Dalli J, Winkler JW, Colas RA, Arnardottir H, Cheng CY, Chiang N, et al (2013) Resolvin D3 and aspirin-triggered resolvin D3 are potent immunoresolvents. Chem Biol 20: 188-201.

129. Chan MM, Moore AR (2010) Resolution of inflammation in murine autoimmune arthritis is disrupted by cyclooxygenase-2 inhibition and restored by prostaglandin E2mediated lipoxin A4 production. J Immunol 184: 6418-6426.

130. Wu B, Walker J, Spur B, Rodriguez A, Yin K (2015) Effects of Lipoxin A4 on antimicrobial actions of neutrophils in sepsis. Prostaglandins Leukot Essent Fatty Acids 94: $55-64$.

131. Walker J, Dichter E, Lacorte G, Kerner D, Spur B, Rodriguez A, et al (2011) Lipoxin a4 increases survival by decreasing systemic inflammation and bacterial load in sepsis. Shock 36: 410-416.

132. Wu B, Capilato J, Pham MP, Walker J, Spur B, Rodriguez A, et al (2016) Lipoxin A4 augments host defense in sepsis and reduces Pseudomonas aeruginosa virulence through quorum sensing inhibition. FASEB J 30: 2400-2410.

133. Das UN (2014) HLA-DR expression, cytokines and bioactive lipids in sepsis. Arch Med Sci 10: 325-335.

134. Das UN (2010) Current and emerging strategies for the treatment and management of systemic lupus erythematosus based on molecular signatures of acute and chronic inflammation. J Inflammation Res 3: 143-170.

135. Das UN (2013) Is sepsis a pro-resolution deficiency disorder? Med Hypotheses 80: 297-299.

136. Das UN (1994) Beneficial effect of eicosapentaenoic acid and docosahexaenoic acid in the management of systemic lupus erythematosus and its relationship to the cytokine network. Prostaglandins Leukot Essen Fatty Acids 51: 207-213.

137. Mayer K, Schmidt R, Muhly-Reinholz M, Bögeholz T, Gokorsch S, Grimminger F, Seeger W (2002) In vitro mimicry of essential fatty acid deficiency in human endothelial cells by TNF $\alpha$ impact of $\omega-3$ versus $\omega-6$ fatty acids. J Lipid Res 43: 944-95 1. 
138. Suryaprabha P, Das UN, Ramesh G, Kumar KV, Kumar KS (1991) Reactive oxygen species, lipid peroxides and essential fatty acids in patients with rheumatoid arthritis and systemic lupus erythematosus. Prostaglandins Leukot Essen Fatty Acids 43: 251-255.

139. Mohan IK, Das UN (1997) Oxidant stress, anti-oxidants and essential fatty acids in systemic lupus erythematosus. Prostaglandins Leukot Essen Fatty Acids. 56: 193-198. 140. Das UN (1995) Beneficial action(s) of eicosapentaenoic acid/docosahexaenoic acid and nitric oxide in systemic lupus erythematosus. Med Sci Res 23: 723-726.

141. Das UN, Ramesh G, Sravan Kumar G, Madhavi N, Vijay Kumar K, Sangeetha Sagar P, Koratkar R, Padma M (1992) Free radicals, lipid peroxidation and essential fatty acids in patients with Pneumonia, septicemia and collagen vascular diseases. J Nutritional Med 3: 117-128.

142. Devi GR, Das UN, Rao KP, Rao MS (1983) Prevention of radiation-induced polychromatophilia by prostaglandin El and colchicine. IRCS Med Sci 11: 863-864.

143. Devi GR, Das UN, Rao KP, Rao MS (1984) Prostaglandins and mutagenesis: Prevention and/or reversibility of genetic damage induced by benzo (a) pyrene in the bone marrow cells of mice by prostaglandins El. Prostaglandins Leukotrienes Med 15: 287-292.

144. Das UN, Devi GR, Rao KP, Rao MS (1985) Benzo (a) pyrene and gammaradiation-induced genetic damage in mice can be prevented by gamma-linolenic acid but not by arachidonic acid. Nutrition Res 5: 101-105.

145. Das UN, Devi GR, Rao KP, Rao MS (1985) Prostaglandins and their precursors can modify genetic damage induced by benzo (a,) pyrene and gamma-radiation. Prostaglandins 29: 911-919.

146. Sridevi K. Rao KP, Das UN (1990) Modification of benzo (a) pyrene induced genetic damage by prostaglandin El: a dose response and time course study. Med Sci Res 18: $473-474$.

147. Das UN, Rao KP (2006) Effect of $\gamma$-linolenic acid and prostaglandins E1 on gamma-radiation and chemical-induced genetic damage to the bone marrow cells of mice. Prostaglandins Leukot Essen Fatty Acids 74:165-173. 
148. Suresh Y, Das UN (2006) Differential effect of saturated, monounsaturated, and polyunsaturated fatty acids on alloxan-induced diabetes mellitus. Prostaglandins Leukot Essen Fatty Acids 74:199-213.

149. Suresh Y, Das UN (2003) Long-chain polyunsaturated fatty acids and chemically induced diabetes mellitus: effect of omega-6 fatty acids. Nutrition 19: 93-114.

150. Suresh Y, Das UN (2003) Long-chain polyunsaturated fatty acids and chemically induced diabetes mellitus: Effect of $\omega-3$ fatty acids. Nutrition 19: 213-228.

151. Devi SMM, Das UN (2004) Effect of prostaglandins against alloxan-induced cytotoxicity to insulin secreting insulinoma RIN cells in vitro. Prostaglandins Leukot Essen Fatty Acids 71: 309-318.

152. Shivani P, Rao KP, Chaudhury JR, Ahmed J, Rao BR, Kanjilal S, Hasan Q, Das UN (2009) Effect of polyunsaturated fatty acids on diphenyl hydantoin-induced genetic damage in-vitro and in vivo. Prostaglandins Leukot Essen Fatty Acids 80: 43-50.

153. Devi GR, Das UN, Rao, KP, Rao MS (1984) Prostaglandins and mutagenesis: Modification of phenytoin-induced genetic damage by prostaglandins in lymphocyte cultures. Prostaglandins Leukotrienes Med 15: 109, 1984.

154. Naveen KVG, Naidu VGM, Das UN (2017) Arachidonic acid and lipoxin A4 attenuate alloxan-induced cytotoxicity to RIN5F cells in vitro and type 1 diabetes mellitus in vivo. BioFactors 2017; 43: 251-271.

155. Naveen KVG, Naidu VGM, Das UN (2017) Arachidonic acid and lipoxin A4 attenuate streptozotocin-induced cytotoxicity to RIN5F cells in vitro and type 1 and type 2 diabetes mellitus in vivo. Nutrition 35: 61-80.

156. Das UN (2020) Bioactive lipids and coronavirus (COVID-19)-further discussion. Arch Med Res 51: 445-449.

157. Huang H, Chen Y, Ye J (2007) Inhibition of hepatitis C virus replication by peroxidation of arachidonate and restoration by vitamin E. Proc Natl Acad Sci U S A 104: 1866-1870.

158. Kawano A, Ariyoshi W, Yoshioka Y, Hikiji H, Nishihara T, Okinaga T (2019) Docosahexaenoic acid enhances M2 macrophage polarization via the p38 signaling pathway and autophagy. J Cell Biochem 120: 12604-12617. 
159. Zhang S, Liu Y, Zhang X, Zhu D, Qi X, Cao X, et al (2018) Prostaglandin $\mathrm{E}_{2}$ hydrogel improves cutaneous wound healing via M2 macrophages polarization. Theranostics 8: 5348-5361.

160. Wang Q, Xu QY, Wu HM, Hua J (2018) Effect of lipid-induced macrophage M1/M2 polarization on lipid metabolism in hepatocytes. Zhonghua Gan Zang Bing Za Zhi 26: 276-281.

161. Park HJ, Kim J, Saima FT, Rhee KJ, Hwang S, Kim MY, et al (2018) Adiposederived stem cells ameliorate colitis by suppression of inflammasome formation and regulation of M1-macrophage population through prostaglandin E2. Biochem Biophys Res Commun 2018; 498: 988-995.

162. Gromovsky AD, Schugar RC, Brown AL, Helsley RN, Burrows AC, Ferguson D, et al (2018) $\Delta-5$ Fatty Acid Desaturase FADS1 Impacts Metabolic Disease by Balancing Proinflammatory and Proresolving Lipid Mediators. Arterioscler Thromb Vasc Biol 38: 218-231.

163. Sorgi CA, Zarini S, Martin SA, Sanchez RL, Scandiuzzi RF, Gijón MA, et al (2017) Dormant 5-lipoxygenase in inflammatory macrophages is triggered by exogenous arachidonic acid. Sci Rep 7: 10981.

164. Talamonti E, Pauter AM, Asadi A, Fischer AW, Chiurchiù V, Jacobsson A (2017) Impairment of systemic DHA synthesis affects macrophage plasticity and polarization: implications for DHA supplementation during inflammation. Cell Mol Life Sci 74: 28152826.

165. Simões RL, De-Brito NM, Cunha-Costa H, Morandi V, Fierro IM, Roitt IM, Barja-Fidalgo C (2017) Lipoxin $\mathrm{A}_{4}$ selectively programs the profile of M2 tumorassociated macrophages which favour control of tumor progression. Int J Cancer 140: 346-357.

166. Pope NH, Salmon M, Davis JP, Chatterjee A, Su G, Conte MS, et al (2016) Dseries resolvins inhibit murine abdominal aortic aneurysm formation and increase M2 macrophage polarization. FASEB J 30: 4192-4201.

167. Kang JW, Lee SM (2016) Resolvin D1 protects the liver from ischemia/reperfusion injury by enhancing M2 macrophage polarization and efferocytosis. Biochim Biophys Acta 1861 (9 Pt A): 1025-1035. 
168. Song MY, Wang J, Lee Y, Lee J, Kwon KS, Bae EJ, Park BH (2016)

Enhanced M2 macrophage polarization in high n-3 polyunsaturated fatty acid transgenic mice fed a high-fat diet. Mol Nutr Food Res 60: 2481-2492.

169. Ramon S, Dalli J, Sanger JM, Winkler JW, Aursnes M, Tungen JE, et al (2016) The protectin PCTR1 is produced by human M2 macrophages and enhances resolution of infectious inflammation. Am J Pathol 186: 962-973.

170. Vasandan AB, Jahnavi S, Shashank C, Prasad P, Kumar A, Prasanna SJ (2016) Human Mesenchymal stem cells program macrophage plasticity by altering their metabolic status via a $\mathrm{PGE}_{2}$-dependent mechanism. Sci Rep 6: 38308. doi: $10.1038 /$ srep38308.

171. Park HJ, Kim J, Saima FT, Rhee KJ, Hwang S, Kim MY, Baik SK, Eom YW, Kim HS (2018) Adipose-derived stem cells ameliorate colitis by suppression of inflammasome formation and regulation of M1-macrophage population through prostaglandin E2. Biochem Biophys Res Commun 498: 988-995.

172. An JH, Song WJ, Li Q, Kim SM, Yang JI, Ryu MO, Nam AR, Bhang DH, Jung YC, Youn HY (2018) Prostaglandin $\mathrm{E}_{2}$ secreted from feline adipose tissue-derived mesenchymal stem cells alleviate DSS-induced colitis by increasing regulatory $\mathrm{T}$ cells in mice. BMC Vet Res 14: 354.

173. Rozenberg A, Rezk A, Boivin MN, Darlington PJ, Nyirenda M, Li R, Jalili F, Winer R, Artsy EA, Uccelli A, Reese JS, Planchon SM, Cohen JA, Bar-Or A (2016) Human mesenchymal stem cells impact $\mathrm{Th} 17$ and Th1 responses through a prostaglandin E2 and myeloid-dependent mechanism. Stem Cells Transl Med 5: 15061514.

174. Wang L, Zhao Y, Shi S (2012) Interplay between mesenchymal stem cells and lymphocytes: implications for immunotherapy and tissue regeneration. J Dent Res 91: 1003-1010.

175. Wang M, Honn KV, Nie D (2007) Cyclooxygenases, prostanoids, and tumor progression. Cancer Metastasis Rev 26: 525-534.

176. Phipps RP, Stein SH, Roper RL (1991) A new view of prostaglandin E regulation of the immune response. Immunol Today 12: 349-352. 
177. Poloso NJ, Urquhart P, Nicolaou A, Wang J, Woodward DF (2013) PGE2 differentially regulates monocyte-derived dendritic cell cytokine responses depending on receptor usage (EP2/EP4). Mol Immunol 54: 284-295.

178. Kalim KW, Groettrup M (2013) Prostaglandin E2 inhibits IL-23 and IL-12 production by human monocytes through down-regulation of their common p40 subunit. Mol Immunol 53: 274-282.

179. Liu X, Qu X, Chen Y, Liao L, Cheng K, Shao C, et al (2012) Mesenchymal stem/ stromal cells induce the generation of novel IL-10-dependent regulatory dendritic cells by SOCS3 activation. J Immunol 189: 1182-1192.

180. Loynes CA, Lee JA, Robertson AL, Steel MJ, Ellett F, Feng Y, Levy BD, Whyte MKB, Renshaw SA (2018) $\mathrm{PGE}_{2}$ production at sites of tissue injury promotes an antiinflammatory neutrophil phenotype and determines the outcome of inflammation resolution in vivo. Sci Adv Sep 5;4(9):eaar8320. doi: 10.1 126/sciadv.aar8320. eCollection 2018 Sep.

181. Chan MM-Y, Moore AR (2010) Resolution of inflammation in murine autoimmune arthritis is disrupted by cyclooxygenase- 2 inhibition and restored by prostaglandin E2-mediated lipoxin A4 production. J Immunol 184: 6418-6426.

182. Das UN. Molecular Basis of Health and Disease. Springer, New York, 2011.

183. Das UN (2020) Bioactive lipids as mediators of the beneficial action(s) of mesenchymal stem cells in COVID-19. Aging Dis 11: 746-755.

184. Chan MM-Y, Moore AR (2010) Resolution of inflammation in murine autoimmune arthritis is disrupted by cyclooxygenase- 2 inhibition and restored by prostaglandin E2-mediated lipoxin A4 production. J Immunol 184: 6418-6426.

185. Zhang Y, Desai A, Yang SY, et al (2015) Inhibition of the prostaglandindegrading enzyme 15-PGDH potentiates tissue regeneration. Science 348: 1223. DOI: $10.1126 /$ science.aaa2340.

186. North TE, Goessling W, Walkley CR, et al (2007) Prostaglandin E2 regulates vertebrate haematopoietic stem cell homeostasis. Nature 447: 1007-1011.

187. Li F, Huang Q, Chen J, et al (2010) Apoptotic cells activate the "Phoenix Rising" pathway to promote wound healing and tissue regeneration. Sci Signal 3(110): ra13. doi:10.1126/scisignal.2000634. 
188. Hoggatt J, Mohammad KS, Singh P, et al (2013) Differential stem- and progenitor-cell trafficking by prostaglandin E2. Nature doi:10.1038/nature 11929.

189. Diaz MF, Li N, Lee HJ, et al (2015) Biomechanical forces promote blood development through prostaglandin E2 and the cAMP-PKA signaling axis. J Exp Med 212: 665-680.

190. Das UN (2020) Can bioactive lipid arachidonic acid prevent and ameliorate COVID-19? Medicina 56: E418. doi: 10.3390/medicina56090418.

191. Das UN (2020) Can bioactive lipids inactivate Coronavirus (COVID-19)? Arch Med Res 51: 282-286.

192. Fang X, Abbott J, Cheng L, Colby JK, Lee JW, Levy BD, Matthay MA (2015) Human Mesenchymal Stem (Stromal) Cells Promote the Resolution of Acute Lung Injury in Part through Lipoxin A4. J Immunol 195: 875-881.

193. Cheng X, He S, Yuan J, Miao S, Gao H, Zhang J, Li Y, Peng W, Wu P (2016) Lipoxin A4 attenuates LPS-induced mouse acute lung injury via Nrf2-mediated Ecadherin expression in airway epithelial cells. Free Radic Biol Med 93: 52-66.

194. Bai Y, Wang J, He Z, Yang M, Li L, Jiang H (2019) Mesenchymal stem cells reverse diabetic nephropathy disease via lipoxin A4 by targeting transforming growth factor $\beta$ (TGF- $\beta$ )/smad pathway and pro-Inflammatory cytokines. Med Sci Monit 25: 3069-3076.

195. Leng Z, Zhu R, Hou W, Feng Y, Yang Y, Han Q, Shan G, et al (2020) Transplantation of ACE2- mesenchymal stem cells improves the outcome of patients with COVID-19 pneumonia. Aging Dis 11: 216-228.

196. Coulombe F, Jaworska J, Verway M, Tzelepis F, Massoud A, Gillard J, Wong G, Kobinger G, Xing Z, Couture C, Joubert P, Fritz JH, Powell WS, Divangahi M (2014) Targeted prostaglandin E2 inhibition enhances antiviral immunity through induction of type I interferon and apoptosis in macrophages. Immunity 40: 554-568.

197. Ono E, Dutile S, Kazani S, Wechsler ME, Yang J, Hammock BD, et al. (2014) Lipoxin generation is related to soluble epoxide hydrolase activity in severe asthma. Am J Respir Crit Care Med 190: 886-897.

198. Caligiuri SPB, Aukema HM, Ravandi A, Guzman R, Dibrov E, Pierce GN (2014) Flaxseed consumption reduces blood pressure in patients with hypertension by altering 
circulating oxylipins via an $\alpha$-linolenic acid-induced inhibition of soluble epoxide hydrolase. Hypertension 64: 53-59.

199. Das UN (1995) Essential fatty acid metabolism in patients with essential hypertension, diabetes mellitus and coronary heart disease. Prostaglandins Leukot Essen Fatty Acids 52: 387-391.

200. Toelzer C, Gupta K, Yadav SKN, Borucu U, Davidson AD, Kavanagh Williamson M, Shoemark DK, Garzoni F, Staufer O, Milligan R, Capin J, Mulholland AJ, Spatz J, Fitzgerald D, Berger I, Schaffitzel C (2020) Free fatty acid binding pocket in the locked structure of SARS-CoV-2 spike protein. Science Sep 21:eabd3255. doi: 10.1126/science.abd3255. Epub ahead of print. PMID: 32958580.

201. Gangemi S, Pescara L, D'Urbano E, Basile G, Nicita-Mauro V, Davì G, Romano $\mathrm{M}$ (2005) Aging is characterized by a profound reduction in anti-inflammatory lipoxin A4 levels. Exp Gerontol 40: 612-614

202. Tateishi N., Kakutani S., Kawashima H (2014) Dietary supplementation of arachidonic acid increases arachidonic acid and lipoxin A4 contents in colon but does not affect severity or prostaglandin E2 content in murine colitis model. Lipids Health Dis 13:30.

203. Tateishi N., Kaneda Y., Kakutani S (2015) Dietary supplementation with arachidonic acid increases arachidonic acid content in paw but does not affect arthritis severity or prostaglandin E2 content in rat adjuvant-induced arthritis model. Lipids Health Dis 14:3.

204. Kakutani S., Ishikura Y., Tateishi N (2011) Supplementation of arachidonic acidenriched oil increases arachidonic acid contents in plasma phospholipids but does not increase their metabolites and clinical parameters in Japanese healthy elderly individuals: a randomized controlled study. Lipids Health Dis 10:241.

205. Giamarellos-Bourboulis E.J., Mouktaroudi M., Adamis T (2004) n-6 Polyunsaturated fatty acids enhance the activities of ceftazidime and amikacin in experimental sepsis caused by multidrug-resistant Pseudomonas aeruginosa. Antimicrobial Agents Chemother 48:4713-4717.

206. Barnes BJ, Adrover JM, Baxter-Stoltzfus A, Borczuk A, Cools-Lartigue J, Crawford JM, et al (2020) Targeting potential drivers of COVID-19: neutrophil extracellular traps. J Exp Med 217(6): e20200652. doi: 10.1084/jem.20200652 
207. Shishikura K, Horiuchi T, Sakata N, Trinh DA, Shirakawa R, Kimura T, Asada Y, Horiuchi (2016) Prostaglandin E2 inhibits neutrophil extracellular trap formation through production of cyclic AMP. Br J Pharmacol 173: 319-331.

208. Spinosa M, Su G, Salmon MD, Lu G, Cullen JM, Fashandi AZ, Hawkins RB, Montgomery W, Meher AK, Conte MS, Sharma AK, Ailawadi G, Upchurch GR Jr (2018) Resolvin D1 decreases abdominal aortic aneurysm formation by inhibiting NETosis in a mouse model. J Vasc Surg 68: 93S-103S.

209. Cherpokova D, Jouvene CC, Libreros S, DeRoo EP, Chu L, de la Rosa X, Norris PC, Wagner DD, Serhan CN

Resolvin D4 attenuates the severity of pathological thrombosis in mice. Blood 134: 14581468.

210. Domingo-Gonzalez R, Martínez-Colón GJ, Smith AJ, Smith CK, Ballinger MN, Xia M, Murray S, Kaplan MJ, Yanik GA, Moore BB (2016) Inhibition of neutrophil extracellular trap formation after stem cell transplant by prostaglandin E2. Am J Respir Crit Care Med 193: 186-197.

211. Spinelli FR, Conti F, Gadina M (2020) HiJAKing SARS-CoV-2? The potential role of JAK inhibitors in the management of COVID-19. Sci Immunol 10.1126/sciimmunol.abc5367 (2020).

212. Song EA, Lim JW, Kim H (2017) Docosahexaenoic acid inhibits IL-6 expression via PPAR $\gamma$-mediated expression of catalase in cerulein-stimulated pancreatic acinar cells. Int J Biochem Cell Biol 88: 60-68. 213. Wang ZF, Li Q, Liu SB, Mi WL, Hu S, Zhao J, Tian Y, Mao-Ying QL, Jiang JW, Ma HJ, Wang YQ, Wu GC (2014) Aspirin-triggered Lipoxin A4 attenuates mechanical allodynia in association with inhibiting spinal JAK2/STAT3 signaling in neuropathic pain in rats. Neuroscience 273: 65-78.

214. Ji JD, Kim HJ, Rho YH, Choi SJ, Lee YH, Cheon HJ, Sohn J, Song GG (2005) Inhibition of IL-10-induced STAT3 activation by 15-deoxy-Delta12,14prostaglandin J2. Rheumatology (Oxford) 44: 983-988.

215. Tan T, Khoo B, Mills EG, Phylactou M, Patel B, Eng PC, et al. (2020) Association between high serum total cortisol concentrations and mortality from COVID-19. Lancet Diabetes Endocrinol DOI: https://doi.org/10.1016/52213-8587(20)30216-3. 
216. Yang YH, Aeberli D, Dacumos A, Xue JR, Morand EF (2009) Annexin-1 regulates macrophage IL-6 and TNF via glucocorticoid-induced Leucine Zipper. J Immunol 183:1435-1445.

217. Souza DG, Fagundes CT, Amaral FA, Cisalpino D, Sousa LP, Vieira AT, Pinho V, Nicoli JR, Vieira LQ, Fierro IM, Teixeira MM (2007) The required role of endogenously produced lipoxin A4 and annexin-1 for the production of IL-10 and inflammatory hyporesponsiveness in mice. J Immunol 179: 8533-8543.

218. Dashti-Khavidaki S, Khalili H (2020) Considerations for statin therapy in patients with COVID-19. Pharmacotherapy 40: 484-486. doi: 10.1002/phar.2397.

219. Zhang X-J, Qin J-J, Cheng X, Shen L, Zhao Y-C, 2, Yuan Y, et al. (2020) Inhospital use of statins is associated with a reduced risk of mortality among individuals with COVID-19. Cell Metab 2020 Jun 24; S1550-4131(20)30316-8. doi: 10.1016/j.cmet.2020.06.015.

220. Das UN (2001) Essential fatty acids as possible mediators of the actions of statins. Prostaglandins Leukot Essential Fatty Acids 65: 37-40.

221. Das UN (2019) Bioactive lipids as mediators of the beneficial actions of statins. J Cardiovasc Pharmacol 74: 4-8.

222. Das UN (2002) Oestrogen, statins and essential fatty acids: Similarity in their actions and benefits-is there a common link? Nutrition 18: 178-188.

223. Das UN (2002) Nitric oxide as the mediator of the anti-osteoporotic actions of oestrogen, statins and essential fatty acids. Exp Biol Med 227: 88-93.

224. Kumar R, Clerc AC, Gori I, et al (2014) Lipoxin A4 prevents the progression of de novo and established endometriosis in a mouse model by attenuating prostaglandin $\mathrm{E}_{2}$ production and estrogen signaling. PLoS One 9: e89742. doi:10.1371/journal.pone.0089742.

225. Russell R, Gori I, Pellegrini C, Kumar R, Achtari C, Canny GO (2011) Lipoxin A4 is a novel estrogen receptor modulator. FASEB J 25: 4326-4337. doi:10.1096/fj.11187658.

226. De Luca G, Cavalli G, Campochiaro C, Della-Torre E, Angelillo P, Tomelleri A, et al (2020) GM-CSF blockade with mavrilimumab in severe COVID-19 pneumonia and 
systemic hyperinflammation: a single-centre, prospective cohort study. Lancet Rheumatol 2020 June 16, https://doi.org/10.1016/S2665-9913(20)30170-3.

227. DiPersio JF, Billing P, Williams R, Gasson JC (1988) Human GranulocyteMacrophage Colony-Stimulating Factor and Other Cytokines Prime Human Neutrophils for Enhanced Arachidonic Acid Release and Leukotriene B4 Synthesis. J Immunol 140: 4315-4322.

228. Starosta V, Pazdrak K, Boldogh I, Svider T, Kurosky A (2008) Lipoxin A4 counter regulates GM-CSF signaling in eosinophilic granulocytes. J Immunol 181: 86888699. doi: 10.4049/jimmunol.181.12.8688.

229. Gemsa D, Kramer W, Brenner M, Till G, Resch K (1980) Induction of prostaglandin E release from macrophages by colchicine. J Immunol 124: 376-380.

230. Peters-Golden M, McNish RW, Davis JA, Blackwood RA, Brock TG (1996) Colchicine Inhibits Arachidonate Release and 5-lipoxygenase Action in Alveolar Macrophages. Am J Physiol 271 (6 Pt 1): L1004-L1013.

231. Mehta P, McAuley DF, Brown M, Sanchez E, Tattersall RS, Manson JJ; HLH Across Speciality Collaboration, UK (2020) COVID-19: consider cytokine storm syndromes and immunosuppression. Lancet 395: 1033-1034. doi: 10.1016/So1406736(20)30628-0. PMID: 32192578 ; PMCID: PMC7270045.

232. Das UN (2014) HLA-DR expression, cytokines and bioactive lipids in sepsis. Arch Med Sci 10: 325-335.

233. Luo W, Zhang JW, Zhang W, Lin YL, Wang Q (2020) Circulating levels of IL-2, IL-4, TNF- $\alpha$, IFN- $\gamma$, and C-reactive protein are not associated with severity of COVID19 symptoms. J Med Virol 2020 Jun 10:10.1002/jmv.26156. doi: 10.1002/jmv.26156. Epub ahead of print. PMID: 32519779; PMCID: PMC7300996.

234. Janowitz T, Gablenz E, Pattinson D, et al (2020) Famotidine use and quantitative symptom tracking for COVID-19 in non-hospitalised patients: a case series. Gut 2020;gutjnl-2020-32 1852. doi:10.1136/gutjnl-2020-321852.

235. Freedberg DE, Conigliaro J, Wang TC, et al (2020) Famotidine Use is Associated with Improved Clinical Outcomes in Hospitalized COVID-19 Patients: A Propensity Score Matched Retrospective Cohort Study. Gastroenterology 2020; So0165085(20)34706-5. doi:10.1053/j.gastro.2020.05.053. 
236. Manjari V, Das UN (1998) Oxidant stress, anti-oxidants, nitric oxide and essential fatty acids in peptic ulcer disease. Prostaglandins Leukot Essen Fatty Acids 59: 401-406. 237. Manjari V, Das UN (2000) Effect of polyunsaturated fatty acids on dexamethasone-induced gastric mucosal damage. Prostaglandins Leukot Essen Fatty Acids 62: 85-96.

238. Das UN, Vijay Kumar K, Ramanjaneyulu E, Joshi N and Dixit VK (1994) Essential fatty acids and their metabolites in duodenal ulcer. Med Sci Res 22: 423-425.

239. Thompson L, Cockayne A, Spiller RC (1994) Inhibitory effect of polyunsaturated fatty acids on the growth of Helicobacter pylori: a possible explanation of the effect of diet on peptic ulceration. Gut 35: 1557-1561.

240. Khulusi S, Ahmed HA, Patel P, Mendall MA, Northfield TC (1995) The effects of unsaturated fatty acids on Helicobacter pylori in vitro. J Med Microbiol 42: 276-282.

241. Hadjadj J, Yatim N, Barnabei L, Corneau A, Boussier J, Smith N, et al (2020) Impaired type I interferon activity and inflammatory responses in severe COVID-19 patients. Science. 2020 369: 718-724. doi: 10.1126/science.abc6027.

242. Wang Z, Pan H, Jiang B (2020) Type I IFN deficiency: an immunological characteristic of severe COVID-19 patients. Signal Transduct Target Ther 2020 Sep 14;5(1):198. doi: 10.1038/s41392-020-00306-4. PMID: 32929061.

243. Gundala NKV, Das UN (2019) Arachidonic acid-rich ARASCO oil has antiinflammatory and antidiabetic actions against streptozotocin + high fat diet induced diabetes mellitus in Wistar rats. Nutrition.66: 203-218.

244. Sham HP, Walker KH, Abdulnour RE, Krishnamoorthy N, Douda DN, Norris


Regulators in Bacterial Pneumonia. J Immunol 200: 2757-2766.

245. Yu S, Xie J, Xiang Y, Dai S, Yu D, Sun H, et al (2019) Downregulation of TNF$\alpha /$ TNF-R 1 Signals by AT-Lipoxin A4 May Be a Significant Mechanism of Attenuation in SAP-Associated Lung Injury. Mediators Inflamm 2019: 9019404. 
246. Premecz G, Markovits A, Bagi G, Farkas T, Földes I (1989) Phospholipase C and phospholipase A2 are involved in the antiviral activity of human interferon-alpha. FEBS Lett 249: 257-260.

247. Hannigan GE, Williams BR (1991) Signal transduction by interferon-alpha through arachidonic acid metabolism. Science 251: 204-207.

248. Mattila P, Ustinov J, Renkonen R (1993) Interferon-gamma induces a phospholipase D-dependent release of arachidonic acid from endothelial cell membranes: a mechanism for protein kinase C activation. Scand J Immunol 38: 197-200.

249. Verlengia R, Gorjão R, Kanunfre CC, Bordin S, Martins De Lima T, Martins EF, Curi R (2004) Comparative effects of eicosapentaenoic acid and docosahexaenoic acid on proliferation, cytokine production, and pleiotropic gene expression in Jurkat cells. J Nutr Biochem 15: 657-665. doi: 10.1016/j.jnutbio.2004.04.008. PMID: 15590269.

250. Hara Y, Miura S, Komoto S, Inamura T, Koseki S, Watanabe C, et al. (2003) Exposure to fatty acids modulates interferon production by intraepithelial lymphocytes. Immunol Lett 86: 139-148. doi: 10.1016/s0165-2478(03)00007-5. PMID: 12644315.

251. Nishiyama A, Cavaglieri CR, Curi R, Calder PC (2000) Arachidonic acidcontaining phosphatidylcholine inhibits lymphocyte proliferation and decreases interleukin-2 and interferon-gamma production from concanavalin A-stimulated rat lymphocytes. Biochim Biophys Acta 1487(1): 50-60. doi: 10.1016/s1388-1981(00)000822. PMID: 11004609.

252. Salo RJ, Maddux NL, Bleam DK (1986) Effect of prostaglandins on interferon synthesis in murine macrophage-like cell lines. Immunobiology 171(1-2):155-163. doi: 10.1016/So 17 1-2985(86)80024-9. PMID: 2423434.

253. Dooper MM, Wassink L, M'Rabet L, Graus YM (2002) The modulatory effects of prostaglandin-E on cytokine production by human peripheral blood mononuclear cells are independent of the prostaglandin subtype. Immunology 107(1):152-159. doi: 10.1046/j.1365-2567.2002.01474.x. PMID: 12225374; PMCID: PMC1782765. 
254. Shryock N, McBerry C, Salazar Gonzalez RM, Janes S, Costa FT, Aliberti J (2013)

Lipoxin $\mathrm{A}_{4}$ and 15-epi-lipoxin $\mathrm{A}_{4}$ protect against experimental cerebral malaria by inhibiting IL-12/IFN- $\gamma$ in the brain. PLoS One 8(4): e61882. doi: 10.1371/journal.pone.0061882. PMID: 23613965; PMCID: PMC3628580.

255. Kawada N, Mizoguchi Y, Shin T, Tsutsui H, Kobayashi K, Morisawa S, Monna T, Yamamoto S (1990) Interferon gamma stimulates prostaglandin E2 production by mouse Kupffer cells. Prostaglandins Leukot Essent Fatty Acids 4O(4): 275-279. doi: 10.1016/0952-3278(90)90049-q. PMID: 2177198.

256. Boraschi D, Censini S, Tagliabue A. Interferon-gamma reduces macrophagesuppressive activity by inhibiting prostaglandin E2 release and inducing interleukin 1 production. J Immunol 133(2): 764-768. PMID: 6330202.

257. Hart PH, Whitty GA, Piccoli DS, Hamilton JA (1989) Control by IFN-gamma and PGE2 of TNF alpha and IL-1 production by human monocytes. Immunology 66(3): 376-383. PMID: 2495247; PMCID: PMC1385223.

258. Vila-del Sol V, Punzón C, Fresno M (2008) IFN-gamma-induced TNF-alpha expression is regulated by interferon regulatory factors 1 and 8 in mouse macrophages. $\mathrm{J}$ Immunol 181(7): 4461-4470. doi: 10.4049/jimmunol.181.7.4461. PMID: 18802049.

259. Matsuura K, Otsuka F, Fujisawa H (1997) Effects of interferons on tumour necrosis factor alpha production from human keratinocytes. Cytokine 10: 500-505.

260. Mann ER, Menon M, Knight SB, Konkel JE, Jagger C, Shaw TN, et al (2020) Longitudinal immune profiling reveals key myeloid signatures associated with COVID19. Sci Immunol 2020 Sep 17;5(51):eabd6197. doi: 10.1 126/sciimmunol.abd6197. PMID: 32943497.

261. Kaneko N, Kuo HH, Boucau J, Farmer JR, Allard-Chamard H, Mahajan VS, et al and Massachusetts Consortium on Pathogen Readiness Specimen Working Group (2020) Loss of Bcl-6-Expressing T Follicular Helper Cells and Germinal Centers in COVID-19. 
Cell. 2020 Aug 19:So092-8674(20)31067-9. doi: 10.1016/j.cell.2020.08.025. Epub ahead of print. PMID: 32877699; PMCID: PMC7437499.

262. Duan YQ, Xia MH, Ren L, Zhang YF, Ao QL, Xu SP, et al (2020) Deficiency of Tfh Cells and Germinal Center in Deceased COVID-19 Patients. Curr Med Sci. 2020 Aug;40(4):618-624. doi: 10.1007/s11596-020-2225-x. Epub 2020 Aug 29. PMID: 32767259; PMCID: PMC7412778.

263. Garvin MR, Alvarez C, Miller JI, Prates ET, Walker AM, Amos BK, et al (2020) A mechanistic model and therapeutic interventions for COVID-19 involving a RASmediated bradykinin storm. Elife 2020 Jul 7; 9: e59177. doi: 10.7554/eLife.59177. PMID: 326337 18; PMCID: PMC7410499.

264. Candelario J, Chachisvilis M (2013) Activity of Bradykinin B2 Receptor Is Regulated by Long-Chain Polyunsaturated Fatty Acids. PLoS One 8(6): e68151. doi: 10.1371/journal.pone.0068151. PMID: 23826374; PMCID: PMC3694885.

265. Lopes AG, Soares AC, Santos DP, Fernandes MS, Leão-Ferreira LR, QuintanaGomes E, Caruso-Neves C (2004) PLA2/PGE2 are involved in the inhibitory effect of bradykinin on the angiotensin-(1-7)-stimulated $\mathrm{Na}(+)$-ATPase activity of the proximal tubule. Regul Pept 117: 37-41. doi: 10.1016/j.regpep.2003.10.001. PMID: 14687699.

266. Kennedy CR, Proulx PR, Hébert RL (1996) Role of PLA2, PLC, and PLD in bradykinin-induced release of arachidonic acid in MDCK cells. Am J Physiol 271(4 Pt 1): C1064-1072. doi: 10.1152/ajpcell.1996.271.4.C1064. PMID: 8897811.

267. Coyne DW, Mordhorst M, Bertrand W, Morrison AR (1989) Bradykinin stimulated PGE2 production is independent of changes in intracellular calcium in MDCK cells. Biochem Biophys Res Commun 161(3):1333-40. doi: 10.1016/0006-291x(89)913892. PMID: 2742591.

268. Serra-Pages M, Torres R, Plaza J, Herrerias A, Costa-Farré C, Marco A, et al (2015) Activation of the Prostaglandin E2 receptor EP2 prevents house dust mite- 
induced airway hyperresponsiveness and inflammation by restraining mast cells' activity. Clin Exp Allergy 45(10):1590-600. doi: 10.1111/cea.12542. PMID: 25823713.

269. Conti P, Reale M, Barbacane RC, Panara MR, Bongrazio M, Theoharides TC (1992) Role of lipoxins A4 and B4 in the generation of arachidonic acid metabolites by rat mast cells and their effect on [3H] serotonin release. Immunol Lett 32(2): 117-123. doi: 10.1016/o165-2478(92)90103-u. PMID: 1612634.

270. Karra L, Haworth O, Priluck R, Levy BD, Levi-Schaffer F (2015) Lipoxin B4 promotes the resolution of allergic inflammation in the upper and lower airways of mice. Mucosal Immunol 8(4):852-862. doi: 10.1038/mi.2014.116. Epub 2014 Dec 3. PMID: 25465 102; PMCID: PMC4454640.

271. Reiner Ž, Hatamipour M, Banach M, Pirro M, Al-Rasadi K, Jamialahmadi T, Radenkovic D, Montecucco F, Sahebkar A (2020) Statins and the COVID-19 main protease: in silico evidence on direct interaction. Arch Med Sci 16: 490-496. doi: $10.5114 /$ aoms.2020.94655.

272. Katsiki N, Banach M, Mikhailidis DP (2020) Lipid-lowering therapy and reninangiotensin-aldosterone system inhibitors in the era of the COVID-19 pandemic. Arch Med Sci 16(3):485-489. doi: 10.5114/aoms.2020.94503. 


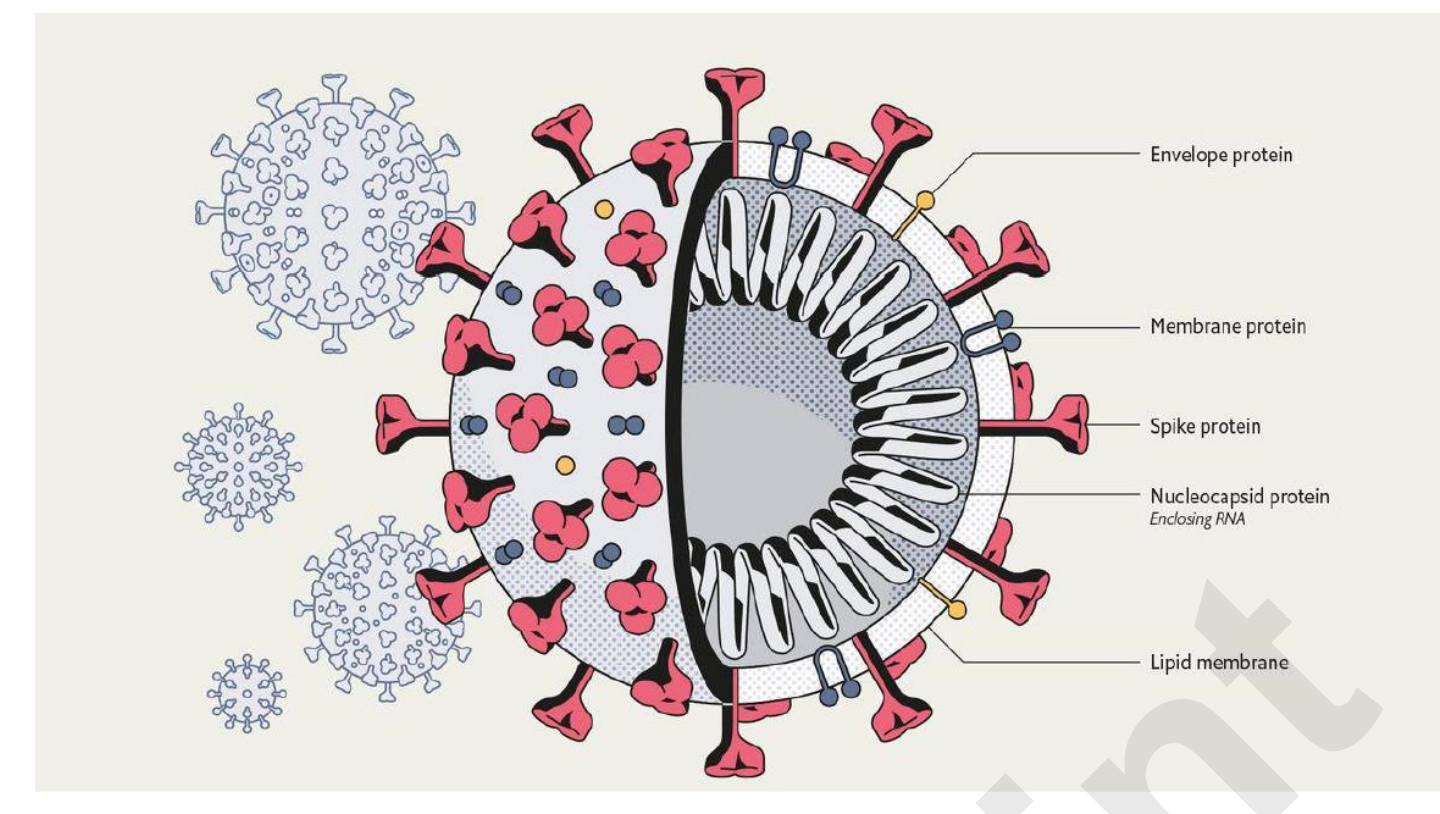

Figure 1A. Structure of SARS-CoV-2 that causes COVID-19. Note the structural similarity with Swine flu virus given in Figure 1B.

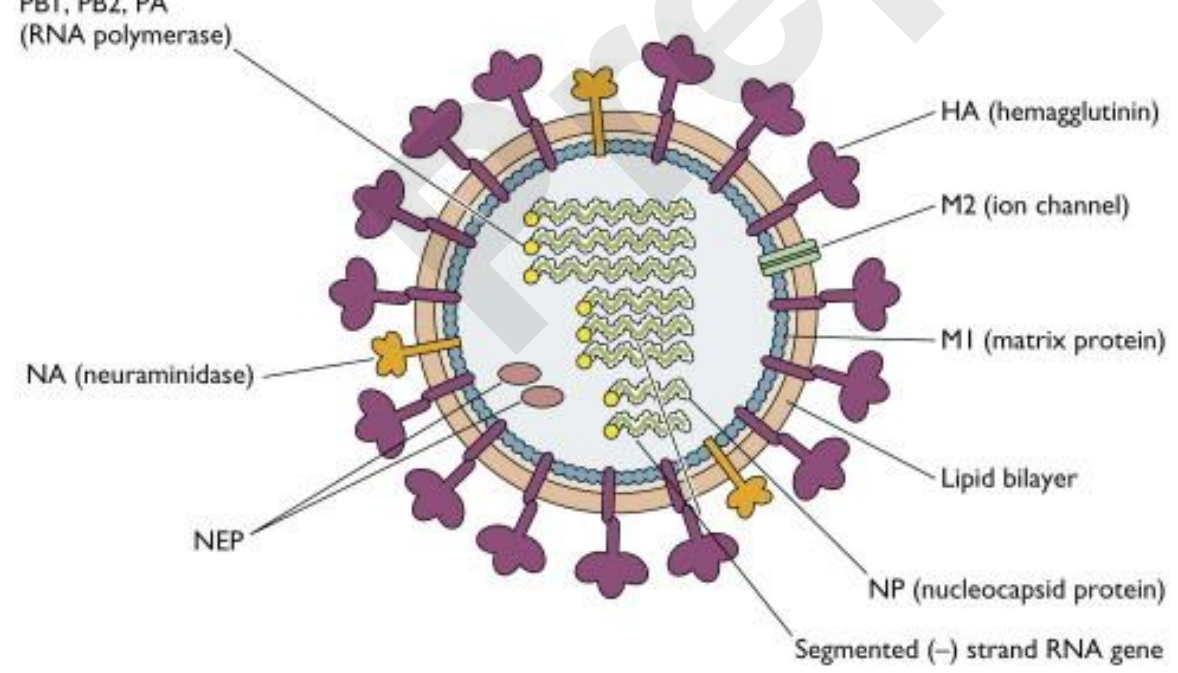

Figure 1B. Structure of the Swine flu A/Mexico/o9 (H1N1) virus.

For comparison between influenza virus and the corona virus see Table 2. 
Table 1. Comparison between Influenza virus and coronavirus (see Figures 1A and 1B also).

\begin{tabular}{|c|c|c|}
\hline S.No & Influenza Virus & Corona virus \\
\hline a. & Family: Orthomyxoviridae & Coronaviridae \\
\hline b. & $\begin{array}{l}\text { Genetic material: ssRNA (mostly) } \\
\text { dsRNA rarely }\end{array}$ & ssRNA \\
\hline c. & Subtypes: A, B, C, D & Alpha, beta, gamma and delta coronavirus \\
\hline d. & $\begin{array}{l}\text { Influenza type } A \text { is most common } \\
\text { with } 12 \text { serotypes }\end{array}$ & $\begin{array}{l}\text { Beta corona virus is the most common subtype } \\
\text { affecting humans }\end{array}$ \\
\hline e. & $\begin{array}{l}\text { Type } B \text { is less common and has } 2-3 \\
\text { times slower mutation rates }\end{array}$ & \\
\hline f. & $\begin{array}{l}\text { Structure: } \\
\text { Size: } 80-120 \text { nm } \\
\text { Envelope: Glycoproteins- } \\
\text { Hemagglutinin responsible for } \\
\text { binding to host cells } \\
\text { Neuraminidase for release of } \\
\text { progeny virus from infected cells } \\
\text { Genome: Mostly Segmented } \\
\text { negative sense RNA } \\
\text { e.g: Type A has } 11 \text { genes on } 8 \\
\text { pieces of negative RNA each } \\
\text { coding for different gene } \\
\text { Replication: RNA dependent RNA } \\
\text { polymerase }\end{array}$ & $\begin{array}{l}\text { Size: } 125 \mathrm{~nm} \\
\text { Envelope: Has lipid bilayer which has } \\
\text { M: membrane } \\
\text { E: envelope } \\
\text { S: spike proteins are anchored } \\
\text { E:S:M= 1:20:300 } \\
\text { Also has short spike ptn: hemagglutinin esterase } \\
\text { Genome: positive ss RNA as bead on strand formation } \\
\text { Size: } 26.4 \text { o } 31.7 \mathrm{~kb} \text { with } 5^{\prime} \text {-mehylated cap and 3'-poly A } \\
\text { tail } \\
2 / 3^{\text {rd }} \text { of genome codes for replicase/transcriptase non- } \\
\text { structural protein. } \\
4 \text { structural proteins are: spike, envelope, membrane } \\
\text { nucleocapsid }\end{array}$ \\
\hline g. & $\begin{array}{l}\text { Incubation time: Short incubation } \\
\text { time }\end{array}$ & 5-6 days, sometimes longer \\
\hline h. & $\begin{array}{l}\text { Secondary infections: less } \\
\text { common }\end{array}$ & Highly prevalent \\
\hline i. & Primary carriers: children & adults \\
\hline j. & Mortality rate: $<0.1 \%$ & $3-4 \%$ \\
\hline
\end{tabular}


Table 2. Clinical features of COVID-19.

A. Asymptomatic: The vast majority of healthy younger people don't develop a critical form of COVID-19. Though, some young people are seriously affected. The risk appears to rise with age and other associated diseases. In persons above the age of 60 and those who have heart disease, lung diseases (including smokers), kidney disease or immune deficiency or had a transplant are more vulnerable and may develop severe disease. However, loss of sense of smell seems to occur in many and have no other symptoms. Currently, it is estimated that $\sim 50-75 \%$ are asymptomatic.

B. Mild COVID-19: Most people below the age of 60 and as many as $\sim 80 \%$ of symptomatic cases will have this form of mild illness that lasts about 710 days. These people may have:

i. $\quad$ Fever in $90 \%$ of cases

ii. Dry cough $(70 \%)$

iii. Tiredness $(40 \%)$

iv. Feeling slightly breathless (20\%)

v. Muscle pans (15\%)

vi. Headache $(15 \%)$

vii. Sore throat $(14 \%)$

viii. Diarrhea $(4 \%)$

ix. Running nose, sore or red eyes and vomiting and low mood may also occur in some.

C. Moderate COVID-19: People with moderate illness that also lasts about 7-14 days are more breathless and have tachycardia, may have cough and increasing breathlessness. The features of moderate COVID-19 include:

i. $\quad$ Temperature $>37.8^{\circ} \mathrm{C}$

ii. Feeling breathless even on moderate exercise such as walking upstairs.

iii. Soreness due to cough

iv. Moderate to persistent cough, several tmes an hour.

v. Headache 
vi. Tiredness even if they stay in bed

vii. A dry mouth.

D. Severe COVID-19: These are the patients who have developed pneumonia. Features of this form of COVID-19 include:

i. $\quad$ Extreme breathlessness-such as unable to speak

ii. Pain in the chest, abdomen or back

iii. A high temperature

iv. Tightness in the chest

v. Anorexia

vi. Confusion

vii. Rapid and shallow breathing

viii. Tachycardia

ix. Looking sick

x. Low blood pressure $(<90 / 60 \mathrm{~mm} \mathrm{Hg})$

E. Critical COVID-19: These are the people who have developed severe pneumonia and are on the verge of developing ARDS or already have developed ARDS. These people may also have sepsis. These are the patients who may need $\mathrm{O} 2$ therapy or ventilatory and other supportive care in a hospital setting.

\section{F. Post-COVID-19 likely complications:}

(i) CVS: myocarditis, $\mathrm{CHF}$, venous and arterial thrombosis.

(ii) Respiratory: persistent dyspnea, cough, lung fibrosis, ?COPD.

(iii) CNS: confusion, memory loss, lethargy, Parkinson's disease, speech defects, tremors, gait abnormalities, venous and arterial thrombosis.

(iv) Immune system: immune complex disease-like picture, increased susceptibility to infections.

(v) Renal system: Renal failure, nephrotic syndrome, nephritis. 
(vi) Endocrine system: Worsening of existing diabetes mellitus or development of diabetes mellitus in a nondiabetic; other endocrine abnormalities may occur but not yet documented.

G. COVID-19 and pregnancy: The impact of SARS-CoV-2 infection on pregnancy and its outcome are not clear. The current evidence indicates that COVID-19 does not have much adverse impact on pregnancy. Newborn to COVID-19 pregnant women do not seem to have any adverse effect. But long-term consequences of mother's SARS-CoV-2 infection on the growth and development of children remains to be established. 


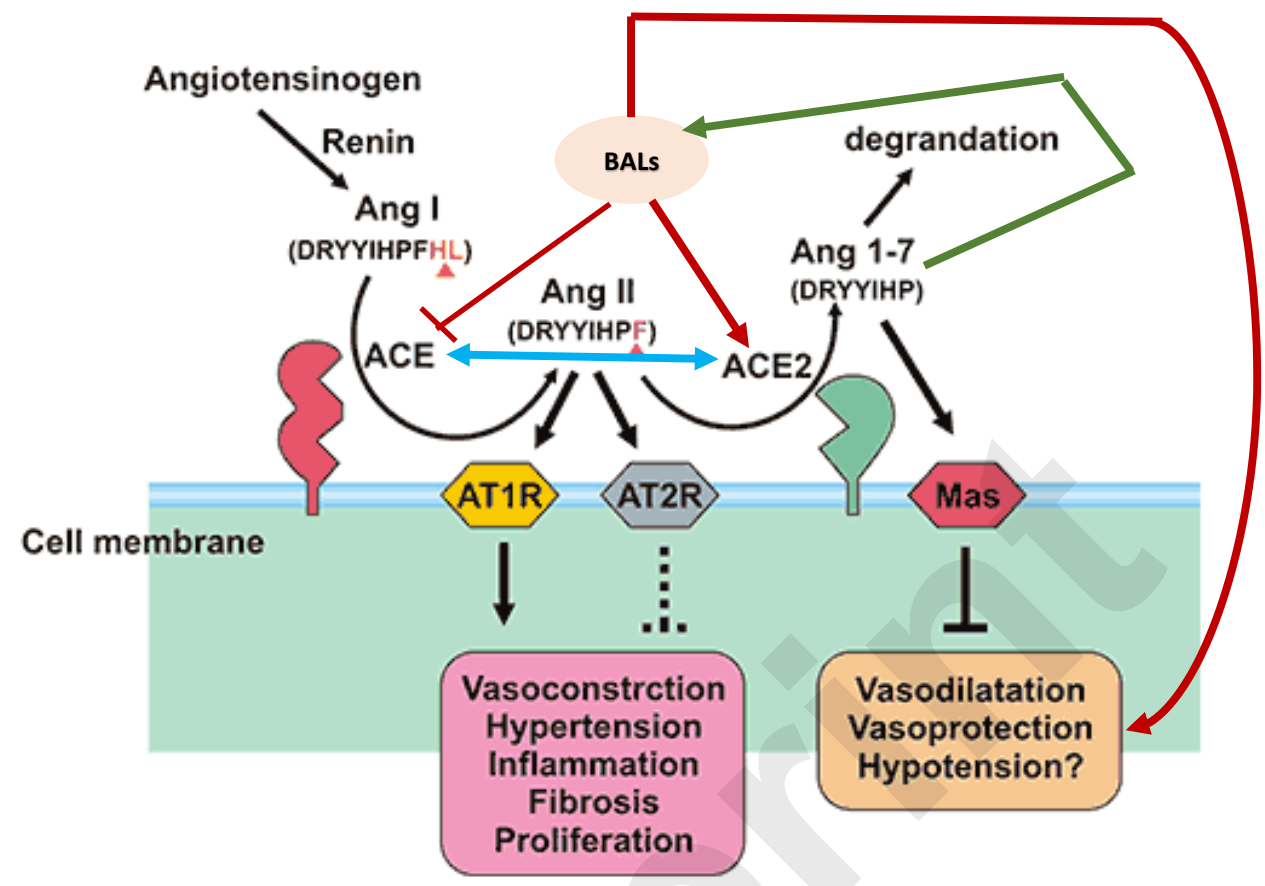

Figure 2. Scheme showing the actions of $\mathrm{ACE}$ and $\mathrm{ACE} 2$ and their role in the regulation of blood pressure, humoral balance, inflammation, cell proliferation, hypertrophy, and fibrosis.

The ACE/AngII/AT1R axis and the ACE2 / Ang 1-7 / MAS axis balance each other. Ang 1-7 is known to restore polyunsaturated fatty acids content of cells to normal especially in diabetes mellitus. Thus implies that there is a close interaction between Ang 1-7 and BALs and possibly some of the beneficial actions of Ang 1-7 on vascular tissue could be due to its actions on EFA metabolism (see Singh K, Singh T, Sharma PL. J Exp Pharmacol 2010: 2: 163-168. DOI: $10.2147 / J E P . S 14342$. 


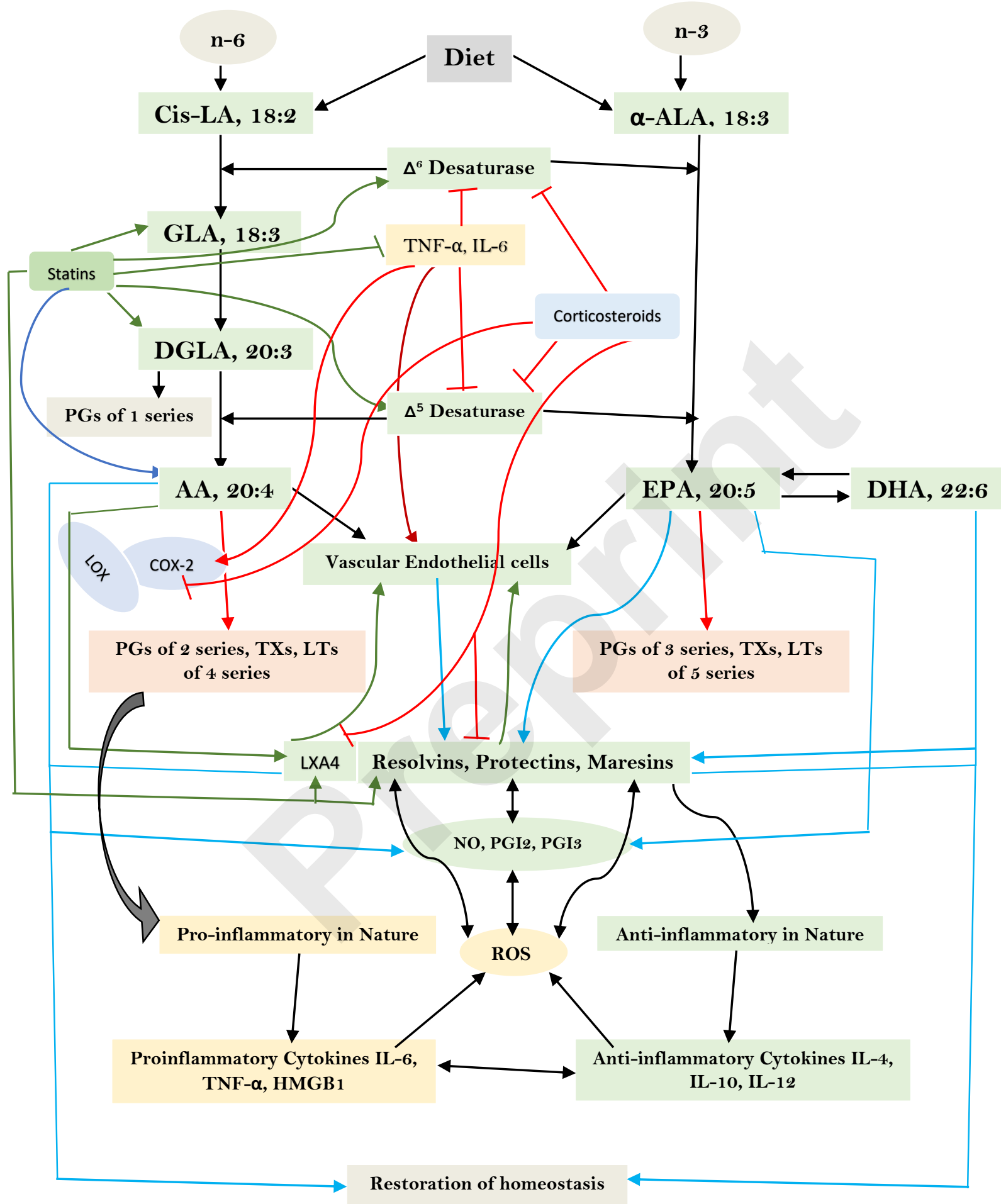


Figure 3A. Scheme showing the metabolism of essential fatty acids, their role in inflammation and cytoprotection of endothelial cells.

Note that corticosteroids block the activity of PLA2, desaturases, COX-2 and LOX and thus, produce EFAs/PUFAs deficiency, inhibit the formation of PGE2 and LTs and of LXA4/resolvins, protectins and maresins. Statins enhance the activities of desaturases and increase the formation of GLA, DGLA, AA and of LXA4/resolvins/protectin/maresins. TNF- $\alpha$ and IL-6 decrease the activity of desaturases and thus, decrease the formation of GLA, DGLA and AA but enhance the activity of COX-2 and thus, produce EFA/PUFAs deficiency but increase the formation of PGE2. TNF- $\alpha$ and IL-6 stimulate PLA2 and thus, increase the release of AA form the cell membrane lipid pool. Thus, both corticosteroids and TNF- $\alpha$ and IL-6 produce EFA/PUFAs deficiency state but have opposite actions on PLA2, and PGE2 formation. 


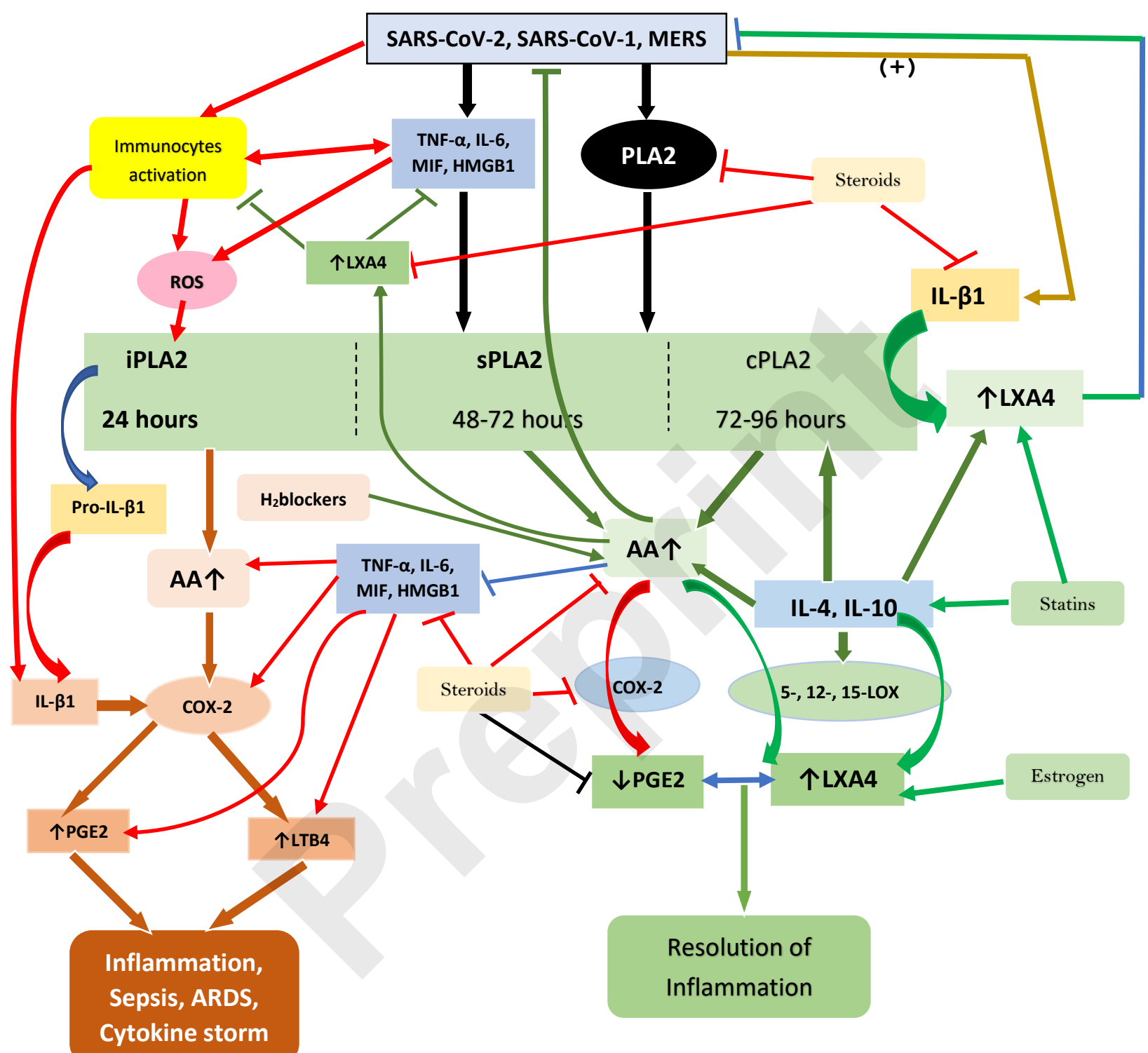

Figure 3B. Scheme showing the relationship among SARS-CoV-2 and other enveloped viruses induced events on EFA metabolism, pro- and anti-inflammatory cytokines and their modulation by steroids and statins. For details see text. Modified from Das UN. J Inflammation Res 3: 143170. 




A

Figure 4. A. Scheme showing potential interaction(s) among invading microbes including SARSCoV-2, host cell (target tissue/cell), immunocytes including macrophages and bioactive lipids including GLA/DGLA/AA/EPA/DHA, LXA4, PGE2, lipid peroxides (LP), activity of PLA2 COX-2 and LOX enzymes, CO, NO, H2S, and soluble epoxide hydrolase (sEH) and their relationship to the ability of microbes to infect the host cell and the response of host cell to infection. B. Similarly, potential interaction between tumor host cell (refers to surrounding normal cells present in the microenvironment of tumor) and the role of COX-2, LOX enzymes and the formation of PGE2/LXA4 and their effect(s) on tumor cell. 


\section{Legend to figure 4:}

(C) When a microbe (including SARS-CoV-2) invades a normal cell (host cell), it may increase the production of PGE2 using its own (or host cell) COX-2. Microbe (using its LPS) or by activating host cell LOX enzymes leads to the formation of LXA4 that negates the synthesis or action of PGE2. Microbial infection activates immunocytes leading to release of IL-6, TNF-a that enhance the production of NO, CO, H2S and other ROS that can kill the microbes. Microbes can also activate PLA2 that induces the release of AA/EPA/DHA from the cell membrane lipid pool that are utilized for the formation of PGE2, LXA4 and lipid peroxides. Depending on the stage of the inflammation initially there will be activation of iPLA2 (inducible phospholipase A2) that induces the release of AA that is directed to form PGE2 and activation of M1 resulting in inflammation. Once PGE2 levels reach the peak it triggers the activation of soluble PLA2 (sPLA2) and cytosolic PLA2 (cPLA2) inducing the release of second wave of AA and simultaneously activation of LOX leading to the formation of LXA4 and M2. This results in suppression of inflammation and restoration of homeostasis. BALS especially AA/EPA/DHA/LXA4 and lipid peroxides kill the microbes including SARS-CoA2. Lipid peroxides, LXA4 and AA/EPA/DHA may inhibit the activity of soluble epoxide hydrolase that leads to suppression of inflammation. Mesenchymal stem cells (MSCs) produce LXA4 to bring about their beneficial actions.

(D) Similar set of events occur in the presence of tumor cell. There is a crosstalk between normal cells surrounding the tumor cell and immunocytes. Tumor cells have high COX2 activity that may lead to increased formation of PGE2 (COX-2 of tumor cells may act on normal cells or on exposure to tumor cells normal cells may enhance their COX-2 activity). On exposure to tumor cell, PLA2 of normal cells/immunocytes is activated to induce the release of $\mathrm{AA} / \mathrm{EPA} / \mathrm{DHA}$ to produce $\mathrm{PGE} 2$ or LXA4. If the released AA/EPA/DHA are converted to form excess of lipid peroxides and/or LXA4, then tumor cell growth is inhibited or undergoes apoptosis. If he activity of COX-2 dominates then AA is converted to PGE2 that induce immunosuppression and enhances tumor cell growth. IL-6 and TNF-a released by immunocytes induce the release of ROS that can 
enhance the formation of lipid peroxides to induce apoptosis of tumor cells. But both IL6 and TNF-a can induce deficiency of AA/EPA/DHA in the tumor cells and surrounding normal cells and immunocytes by inhibiting the activities of desaturases.

See text for further details. 


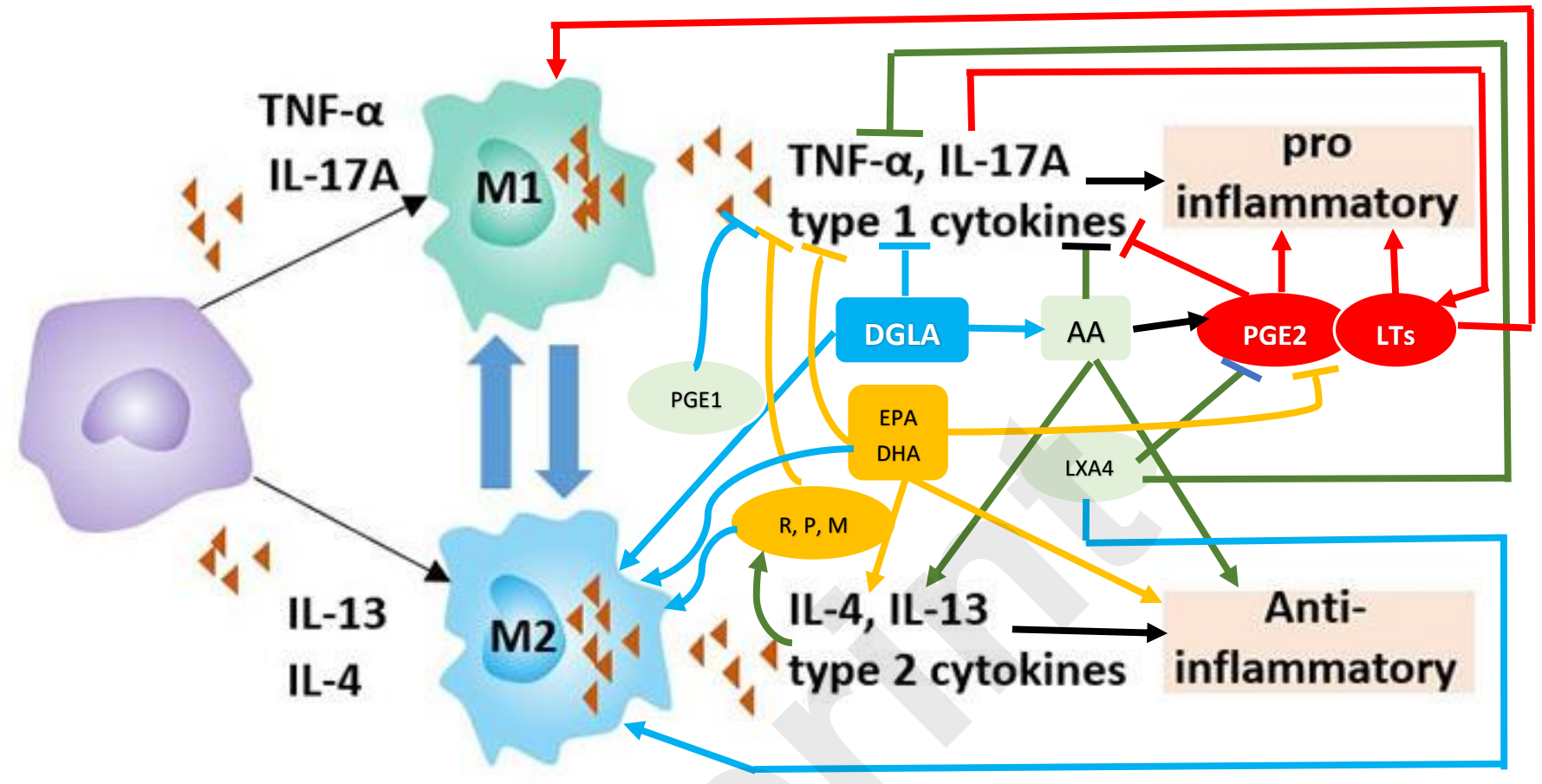

Figure 5. Scheme showing M1 and M2 macrophages and various cytokines produced by them and their respective functions.

DGLA, AA, EPA and DHA have anti-inflammatory actions and inhibit the production of proinflammatory TNF- $\alpha$, IL-2 and IL-1 and facilitate the generation of M2 macrophages.

PGE 1 formed from DGLA, LXA4 from LXA4 are anti-inflammatory in nature.

Resolvins $(\mathrm{R})$, protectins $(\mathrm{P})$, and maresins $(\mathrm{M})$ formed from EPA and DHA are antiinflammatory and block the production of TNF, IL-1, IL-2.

PGE2, Leukotrienes B4, D4 and E4 formed from AA are pro-inflammatory in nature.

LXA4, resolvins, protectins and maresins inhibit the production of PGE2 and LTs.

Leukotrienes (of 5 series) are also formed from EPA that have pro-inflammatory action but are much less potent compared to LTs formed from AA.

EPA and DHA inhibit the production of PGE2. 


\section{Normal homeostasis}
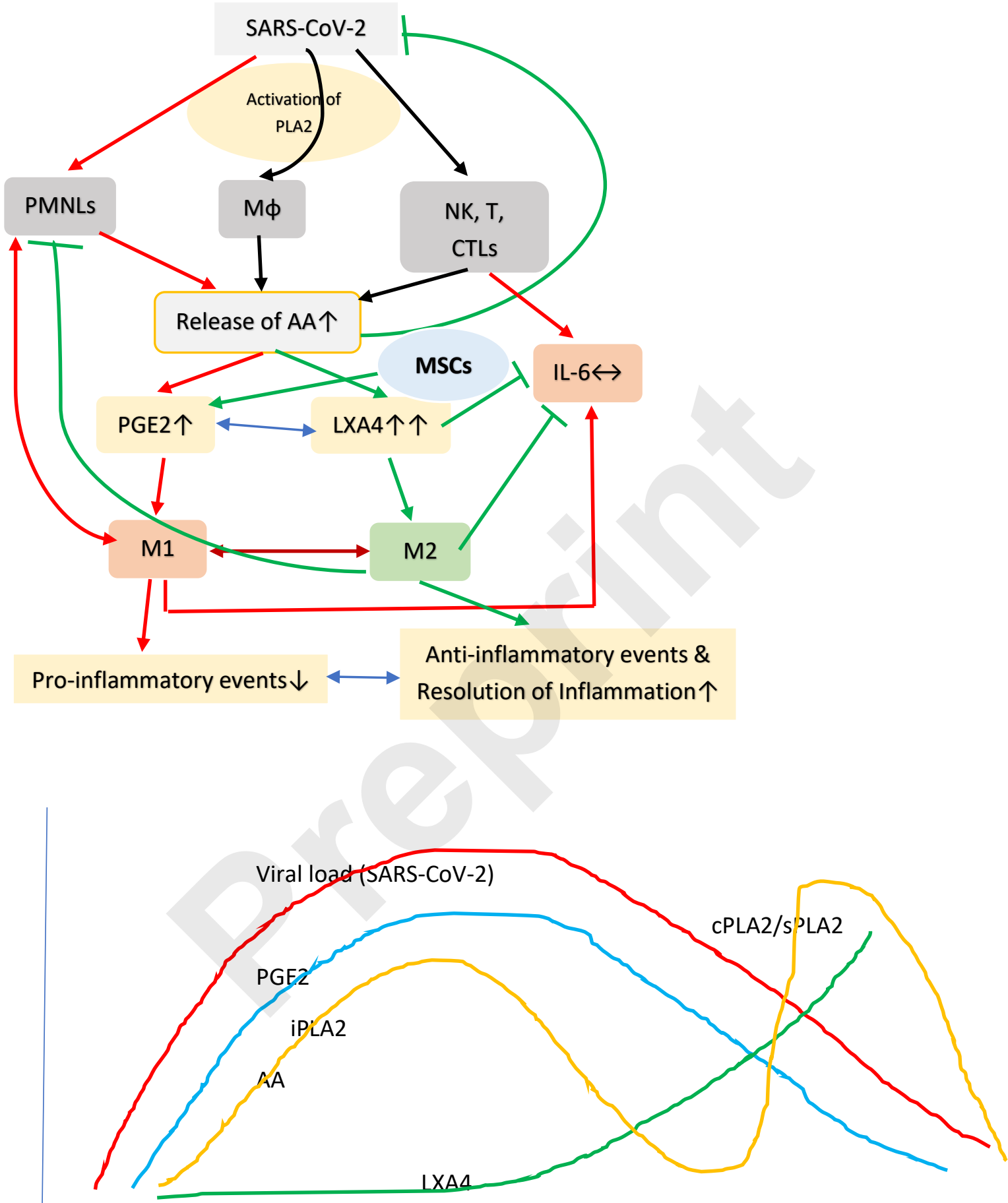

Figure 6A. Scheme showing potential relationship among AA, PGE2, LXA4 and viral load in a COVID-19 patient who recovers. AA is released from the cell membrane in two phases, first 
phase is used for PGE2 synthesis, whereas the second phase is meant for LXA4 synthesis. Once PGE2 concentration reaches its peak, LXA4 synthesis is triggered that induces resolution of inflammation. AA release is triggered by SARS-CoV-2 and other infections. 


\section{Severe COVID-19 (SARS-CoV-2) with ARDS}


Figure 6B. Scheme showing potential relationship among AA, PGE2, LXA4 and viral load in a COVID-19 patient who succumbs to the disease. Absence of biphasic nature of AA release and 
failure of PGE2 to reach its peak to trigger LXA4 synthesis that results in failure of resolution of inflammation fails (compare with Fig 7A). DGLA, EPA and DHA (not shown in the figure) may have actions/functions like AA. Desaturases activities fall with age. 


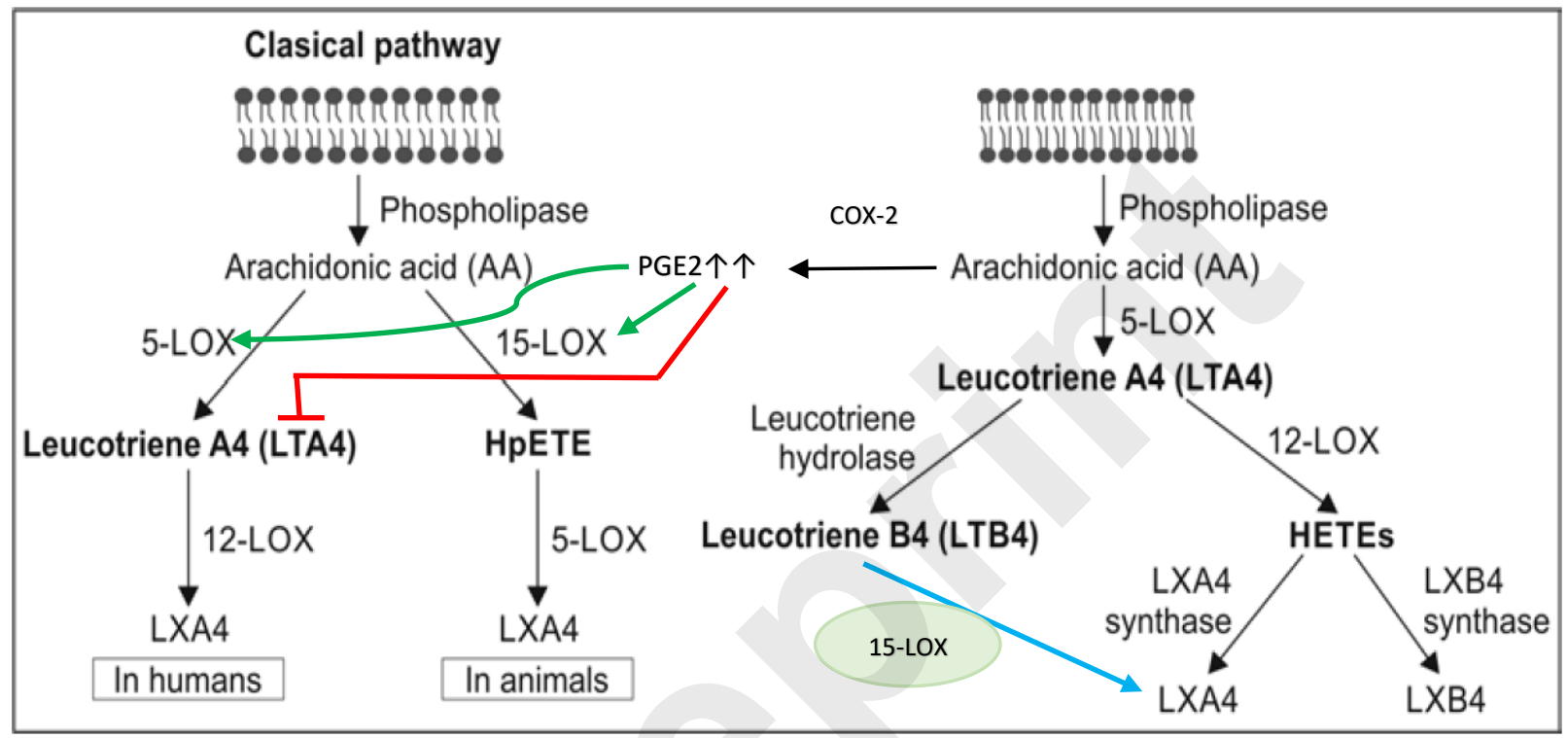

Figure 7. Scheme showing the metabolism of AA and how pro-inflammatory LTA4 can be converted to anti-inflammatory LXA4 by the action of PGE2. Similar conversion of proinflammatory PGs, TXs and LTs to anti-inflammatory resolvins, protectins and maresins may occur. 




Figure 8. Scheme of events that are likely to occur in SARS-CoV-2 infection and the two phases of cytokine response in COVID-19. Initially there will be hyperinflammation due to release of excess of pro-inflammatory cytokines. Subsequently there could occur diminished release of cytokines and immunosuppression. During the hyperinflammation phase dexamethasone and anti-TNF or anti-IL-6 and other cytokine antagonists will be helpful. Once immunosuppression sets in dexamethasone is not of significant help and inflammation resolution molecules are needed to enhance recovery process. In severe COVID-19 there will be persistently elevated PGE2 and LXA4 fails to rise to induce resolution of inflammation. In contrast, in mild COID-19, initially there will be an elevation in PGE2 that falls to the normal physiological level that is accompanied by increase in LXA4 to induce resolution of inflammation as shown in the figure. Compare this with figure 9. This figure is modified from Das UN. Arch Med Sci 2014; 10: 325-335. 

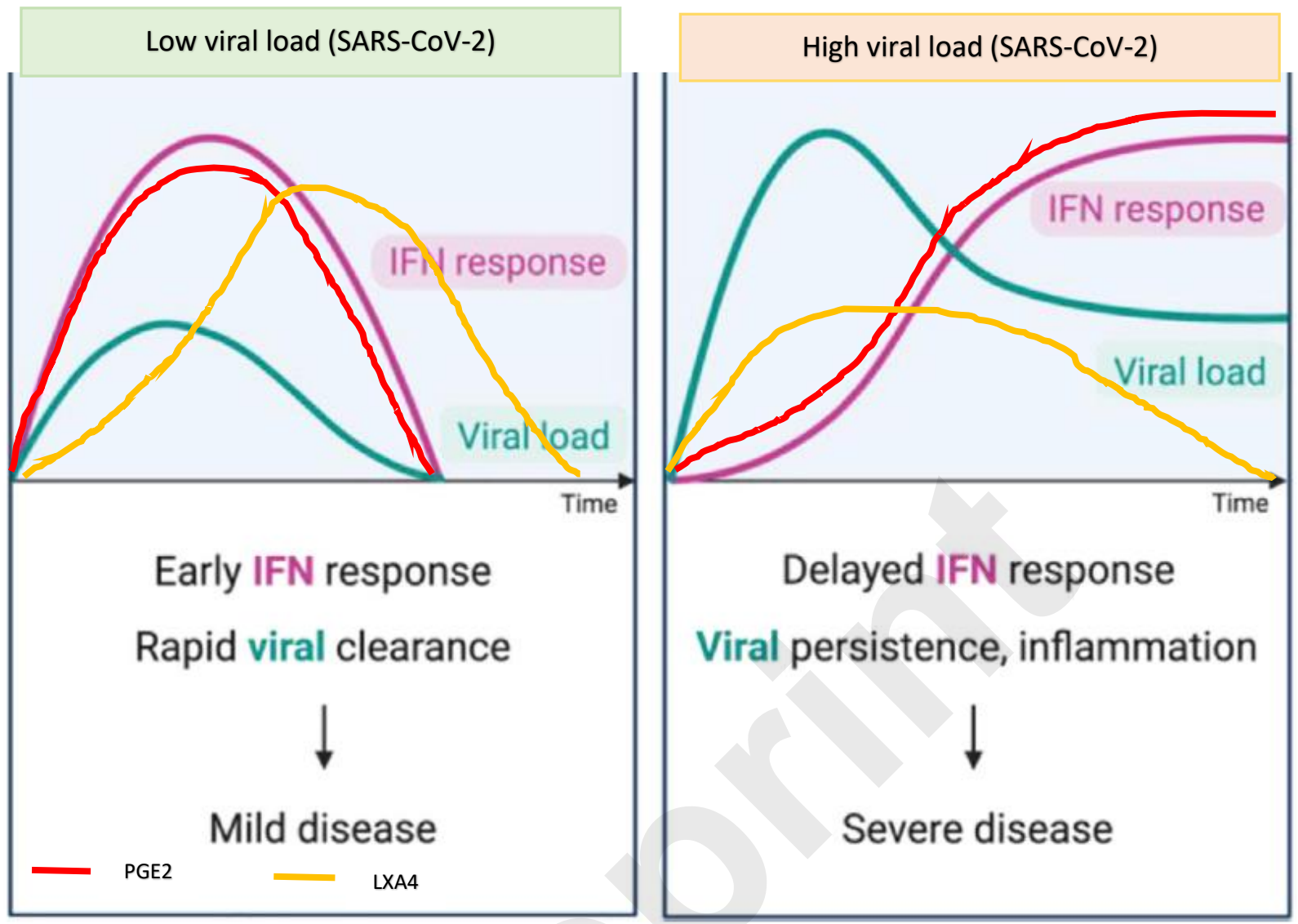

Figure 9. Viral and host factors influence IFN response. When the viral burden is low, IFN production will be adequate to clear the viral infection effectively that is probably accompanied by initial PGE2 response and timely LXA4 generation to resolve inflammation. When viral load is high, virus itself may suppress IFN production and stimulate strong PGE2 and weak LXA4 responses leading to severe COVID-19. Late onset IFN response may aggravate inflammation as seen in severe COVID-19. PGE2 response may parallel IFN response. AA release will occur in both mild and severe SARS-CoV-2 infection, but the product formed and their concentrations (PGE2 and LXA4) may differ as shown in the figure. Compare this with figures 5 and 6. 




Figure 10. Scheme showing interaction among SARS-CoV-2, host cells, immunocytes, AA and cytokines. Similar interaction may exist among SARS-CoV-2, host cells/immunocytes, $\mathrm{EPA} / \mathrm{DHA}$ and resolvins, protectins and maresins. 


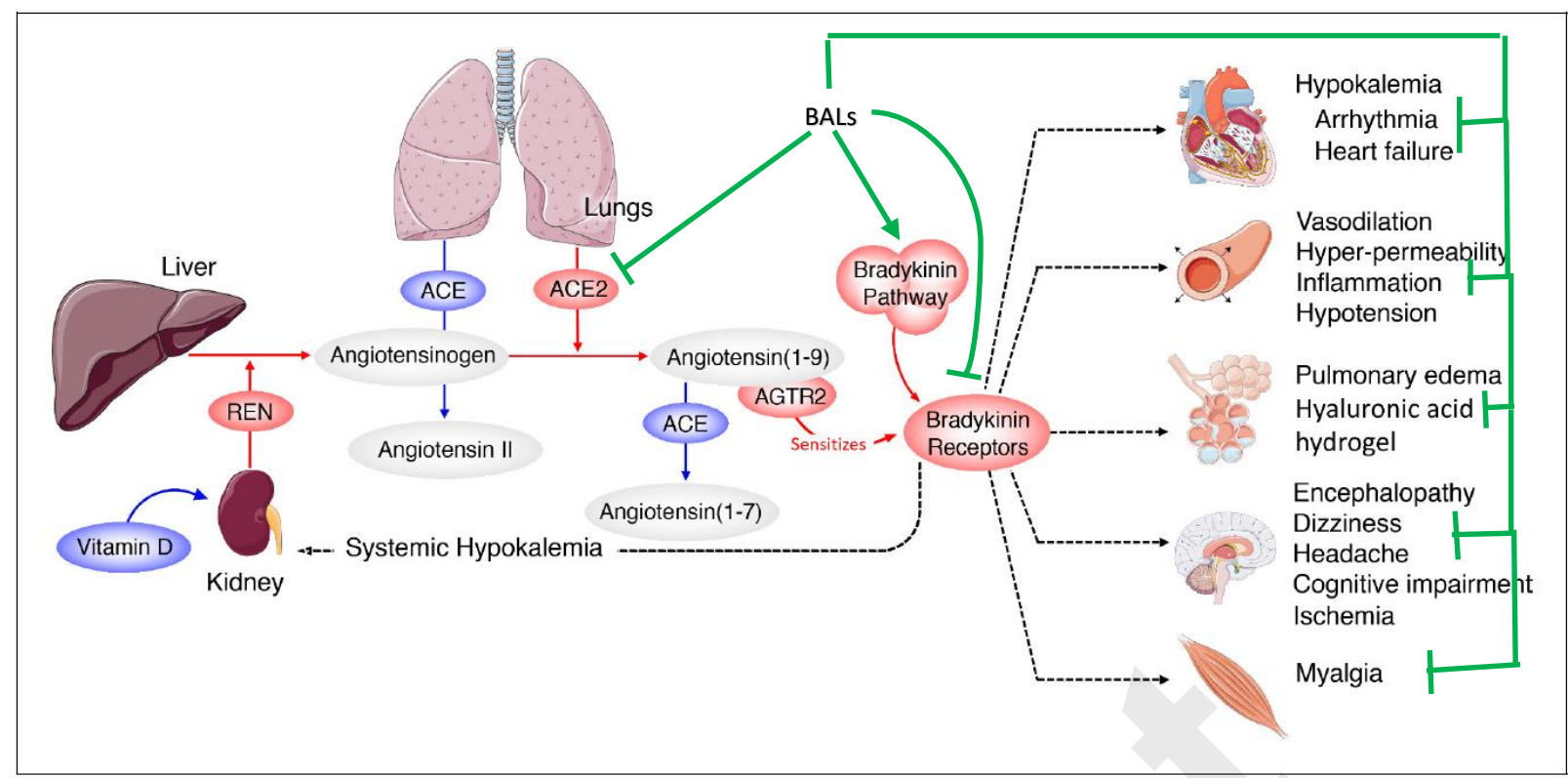

Figure 11. Scheme showing potential involvement of bradykinin in severe COVID-19 as proposed by Garvin et al (263) and how it could be modulated by BALs. 